Die südlichste Zone der Vögel wird characterisiert durch Lestris maccormicki, Pagodroma nivea, Thalassoeca antarctica, Pygoscelis adeliae und Aptenodytes forsteri, welche - abgesehen von einer Varietät oder besonderen Art von Pagodroma, P. nivea var, novegeorgica, die auf Süd - Georgien brütet - die Eiskante nicht verlassen und ganz der Antarktis angehören.

\title{
Eine Reise nach Griechenland und ihre ornithologischen Ergebnisse.
}

\section{Von Dr. Parrot, München.}

In den Tagen, da aus der Feder unseres verdientesten Balkanforschers, Othmar Reiser, eine ausführliche Ornithologie von Griechenland erscheinen wird, mag es ein kühnes Unterfangen sein, noch Neues über den gleichen Gegenstand bringen zu wollen. Der stolze Bau der Reiser'schen Forschungsarbeit ist ja entschieden jetzt schon zu einem gewissen Abschluss gelangt, aber kleine Bausteine, die zur Vollendung des Ganzen beitragen, oder seiner detailierten Ausschmückung dienen können, werden noch immer willkommen sein; als solche mögen die Ergebnisse einer von mir im Frühjahr 1904 in das klassische Land der Hellenen unternommenen Exkursion betrachtet werden.

Ein Aufenthalt an der Südküste des Peloponnes, der um diese Jahreszeit auch von unserem Balkanforscher nie besucht worden war, sollte hauptsächlich der Erkundung des Frühjahrszugs dienen, aber auch diesmal, ähnlich wie auf meiner ägyptischen Reise, wo ich etwas zu spät daran war, entsprachen die Resultate nicht ganz den gehegten Erwartungen; entgegen meiner Überlegung war der Vogelzug, soweit er sich nicht überhaupt der Wahrnehmung entziehen musste, für diesen, man sollte meinen, erstklassigen Beobachtungspunkt den ganzen März hindurch kaum nennenswert, indem ich die Erfahrung machte, dass nicht nur die Zurückkunft vieler dort heimischer Vögel lange auf sich warten liess, sondern dass besonders ein lebhafterer Durchzug nördlicher Arten so ziemlich fehlte; es war auch der Eintritt des Frühlings in diesem Jahre ein durchaus verspäteter, was um so auffälliger erscheinen musste, als nach Aussage der dortigen Jäger ein ausnehmend milder Winter (so zwar, dass nicht einmal die heiss ersehnten Waldschnepfen in gewohnter Menge eintreffen wollten) vorher gegangen war.

Hier zunächst die kurze Schilderung meiner Reise: Nachdem ich am 10. März München verlassen und in rascher Fahrt den nuch im tiefen Schnee liegenden Brenner passiert, sowie das fast noch winterlicher sich präsentierende Pustertal durcheilt hatte, fand mich das nächste Morgengrauen bereits in den wärmeren Strichen des zum adriatischen Meere abfallenden Küstengebietes. 
Triest war um 7 Uhr früh erreicht und nach Erledigung einiger Kommissionen schiffte ich mich auf dem kleinen Dampfer "Samo “" der griechischen Gesellschaft „Panhellenios“ ein. Einstweilen erfreute ich mich an dem munteren Spiele ziemlich zahlreicher Mittelmeer-Silbermöwen (Larus argentatus crchinnans Pall.) -- meist alter Exemplare mit hochgelbem Schnabel und solchen Latschen -, welche neben noch häufigeren Lachmöwen, jungen und alten Tieren (letztere schon mit total braunen Köpfen) den Freihafen belebten. Erst um 3 Uhr nachmittags lichtete die "Samos" die Anker. In der Richtung gegen Schloss Miramar erhob sich bald darauf eine Gesellschaft von c. $110 \mathrm{Stu}$ r m ta u c he r n (wohl Puffinus puffinus yelkouan Acerb.) die in langer Reihe über die glatte Oberfläche des Meeres dahin eilten und nachher in gleicher Anordnung sich darauf niederliessen. Obwohl ich, angeregt durch diese Beobachtung, in der Folge eifrig nach Seevögeln Umschau hielt, wollte sich an diesem Tage kein anderer mehr beim Schiffe zeigen. Des andern Morgens aber um 8 Uhr bot sich mir ein ganz ungewohnter, prächtiger Anblick. Die Möwen, welche hinter dem Schiffe hersegelten, waren keine Lachmöwen, wie man zuerst meinen konnte, sondern sie entpuppten sich alsbald als Schwarzkopfmöwen (Larus melanocephalus Natt.), meist alte Vögel, allerdings mit verschieden vorgeschrittener Ausfärbung der schwarzen Kopfpartien, die meist nur Hinterkopf und Vorderhals einnahmen und nur bei einem anscheinend ganz alten Exemplar, das lediglich ein weisses Fleckchen hinter dem Auge aufwies, schon vollständig entwickelt waren; lebhaft kontrastierte damit der relativ starke Schnabel, der wie die Füsse hochkorallrote Farbe zeigte. Ein Exemplar liess nur einen schwarzen Ohrfleck erkennen, bei allen aber schienen die Flügel vollständig weiss. Es gewährte Vergnügen, diesen prächtigen Vögeln - meist waren es 8 Stück, vorübergehend vermehrten sie sich auf 15 bis 16 - die bis nachmittags das Schiff begleiteten, um dann nach und nach hinter ihm zurück zu bleiben, zuzusehen. Ausser ihnen bemerkte ich nur einmal noch einen Flug weissbäuchiger Vögel, es schienen Totaniden, nach Norden ziehend. Gegen Abend stellten sich 8 Silbermöwen ein, als wir uns etwa auf der Höhe von Lyssa befanden; es war schon ganz dunkel geworden, als einige noch immer dem Dampfer folgten. Der nächste Tag, der 13. März, an dem Land überhaupt nicht zu sehen war, bot eine ganz veränderte Physiognomie, da das bisher völlig ruhig daliegende Meer bei entgegenstehendem Winde sehr bewegt sich zeigte. Nur vorübergehend liessen sich Möwen beim Dampfer blicken; um $1 / 22$ Uhr nachmittags kamen etwa 20 ammerartige $\mathrm{V}$ ögel mit lautem ,zi zi“" auf denselben zu, überflogen ihn nach kurzem Zögern und verschwanden dann, sich etwas senkend, und sich sichtlich gegen den von der Seite kommenden Wind anstemmend, in genau östlicher Richtung aus dem Gesichtskreis; sie schienen durch die südliche Luftströmung zu weit nach Norden 
getrieben und waren offenbar bestrebt, das dalmatinische Festland zu gewinnen. Gleich nachher zogen 6 Grosse Kormorane in ostnordöstlicher Richtung vorüber. Die Beobachtungen an umherirrenden Wanderern hätten an diesem Tage wohl noch recht abwechslungșreich werden können, doch vergeblich kämpfte ich gegen das Überhandnehmen eigener Indisposition an, bis mich endlich die heimtückische See-Krankheit für 40 Stunden(!) ganz in ihre Fesseln schlug und für die Beobachtung der Aussenwelt gleichgültig machte. - Diese Unfähigkeit legte sich erst gegen Mittag des nächsten Tages, wo ich zunächst wieder einige Larus melanocephalus beim Dampfer konstatieren konnte (darunter ein altes ausgefärbtes Männchen), und nach unserer Einfahrt in die Bucht von Korfu verschiedene alte Silbermöwen - diesmal mit scheinbar dunklerem, mausgraublauem Mantel - und einen Grossen Kormoran bemerkte.

Nach kurzem Aufenthalte im Hafen von Korfu ging es weiter nach Süden, auf mir schon bekannten Pfaden zwischen den griechischen Inseln hindurch; von Meeresvögeln war hier wieder gar nichts zu sehen. Noch eine Nacht an Bord und am 15. kurz nach Mittag legten wir in Patras an. Von dem Freunde unseres Vereinsmitgliedes E.l. Pantasopulos, Herrn Demetrios Lalios bewillkommt und rasch durch die Douanne gelotst, war ich bald im Hôtel Patras installiert. Froh, nach dieser nicht immer sehr erquicklichen Fahrt wieder festen Boden unter den Füssen zu haben, besah ich mir sofort die nähere Umgebung der Stadt und erfreute mich an der üppigen Vegetation der Gärten, die sich freilich hauptsächlich auf immergrüne Gewächse und auf niedriges Strauchwerk beschränkte, da die grösseren Bäume sich noch unbelaubt erwiesen. An Vögeln bot sich nichts bemerkenswertes: Grünlinge, Distelfinken, Kohl- und andere Meisen, viele Haussperlinge, welche auf einer Silberpappelgruppe ein Massenkonzert veranstalteten, und als erster Vorbote des Frühlings eine einzelne Rauchschwalbe, das war alles. Bei einem abendlichen Spaziergange am Gestade des Golfes, an dem ein recht unzeitgemässes "Nordlüfterl" wehte, beobachtete ich eine einzelne Seeschwalbe, jedenfalls Sterna nilotica, die erst vor kurzem aus dem Süden zurückgekehrt sein mochte.

Am nächsten Morgen bestieg ich den Peloponnes-Bahnzug, der mich in 10 stündiger, äusserst langsamer, aber grösstenteils sehr genussreicher Fahrt, erst durch die überaus fruchtbare, teilweise mit lichtem Wallonia-Eichenwald bestandene elische Ebene, dann lange Zeit nahe der Küste hin und schliesslich über das rauhe Karstgebirge, in die grosse messenische Ebene und nach meinem vorläufigen Reiseziel, nach Calamata (Kalamä) brachte. Dieser Tag mit seiner warmen wohligen Frühlingsluft, mit einem wolkenlosen tiefblauen Himmel, wie er mir fast während der ganzen Reise nicht mehr bescheert wurde, war recht danach an- 
getan, meine Erwartungen auf das Höchste zu spannen und meinen Erkundungen auch im ornithologischen Sinne einen günstigen Abschluss zu verheissen. Waren die weiten Felder im nördlichen Teil des Peloponnes, besonders in Achaia, schon von zahlreichen Flügen von Kleinvögeln belebt, so schienen die südlicher gelegenen Gestade, wie sie im herrlichstem Schmucke der wunderbar malerischen Aleppo-Kiefern und gelbblühenden Ginstergebüsche prangten, geradezu eine ideale Raststätte für ankommende Wanderer zu bilden. Davon war nun im Vorbeifahren nur recht wenig zu sehen, und es hätte wohl auch ein Besuch dieser Gegenden, den ich damals für später in's Auge gefasst hatte, aber dann nicht zur Ausführung brachte, nach meinen Erfahrungen an anderen ähnlich gearteten Stellen nur mit einer Enttäuschung geendet, denn der Vogelreichtum würde um diese Jahreszeit gewiss nur ein geringer gewesen sein. Überaus häufig zeigte sich jetzt nur die Elster, lange nicht so zahlreich Corvus cornix; einmal drang der Ruf des Cettisängers herein und bei Kaiapha, wo die Berge näher an die Bahn herantreten, sah ich ein Schwarzkehlchen und einige Turmfalken; die Strandkieferwälder aber schienen ganz unbelebt.

In Calamata, der reizend gelegenen Hauptstadt Messeniens, auf das herzlichste von meinem langjährigen Freunde $u$. Kollegen Dr. Elias Pantas opulos empfangen, richtete ich mich für einige Zeit in dem komfortablen Hotel Panhellenios häuslich ein und noch am gleichen Abend sollte ich die Pracht der namentlich aus Orangen- und Zitronen-, teilweise auch Bananenpflanzungen bestehenden Gärten bewundern, welche im Schmucke der zur vollständigen Reife gelangten riesigen und geradezu massenhaft vorhandenen Früchte einen wunderbaren Anblick gewährten und zusammen mit den gleichzeitig entwickelten neuen Blüten einen Duft ausströmten, der Nachts, wenn der furchtbare Strassenstaub sich etwas gelegt hatte, sich über die ganze Stadt verbreitete. Beladen mit solchen Blüten und Früchten und mit Blumen verschiedenster Art, die mir von allen Seiten überreicht wurden, traten wir am Abend den Heimweg an. - -

Die Tage meines Calamater Aufenthaltes brachten mir viel des Interessanten und Neuen, aber in ornithologischer Beziehung hätten die täglich unternommenen Ausflüge in die weite messenische Ebene, an den Strand oder in die hinter der Stadt aufragenden Berge entschieden weit mehr bieten können. Es war aber offenkundig, dass ein nennenswerter Vogeldurchzug, wie er vielleicht an diesem so günstig gelegenen Punkte zu erwarten gewesen wäre, wenn das Wetter sich entsprechend gestaltet hätte, nicht in die Erscheinung trat und dass die beobachteten Vögel zum grössten Teil, abgesehen von den auffallend spärlich vertretenen Standvögeln, Ankömmlinge waren, die hier oder doch in der Nähe ihren Sommeraufenthalt nehmen wollten. Es wehten meist mässige linde Süd-, auch Westwinde föhnischen Charakters, 
welche des öfteren von Regen begleitet wurden. Was an frischen Ankömmlingen sich konstatieren liess - an manchen Tagen war allerdings der Einfluss der Witterung unverkennbar (Südwind!) - mochten bloss die relativ spärlichen Reste der vielleicht nachts obenhingegangenen Vogelzüge sein. Aber auch die Einwanderung der hier heimischen war eine offenbar zögernde; unter diesen Umständen liess sich eine ev. verfrühte Ankunft der empfindlicheren Sommervögel kaum gewärtigen. So blieben die Steinschmätzer, Schafstelzen, weichlichen Grasmücken-Arten während meines Aufenthaltes vollständig aus. Man sagte mir wiederholt, dass nur von Norden kommende starke Luftströmungen geeignet seien, den Vogelzug in lebhaftere Erscheinung treten zu lassen, indem dann die Wanderer, so namentlich riesige Entenscharen, in ihrem Weiterzuge aufgehalten würden. Dass diese negativen Erfahrungen doch eines gewissen Interesses für mich nicht ermangelten, lässt sich denken.

Ganz auffallend war mir die Vogelarmut in den Olivenhainen, welche besonders an den Berghängen sich hinaufziehen. Sehr wenig zeigten sich auch die überaus zahlreichen, spärlich bebuschten Gräben belebt, die samt und sonders ausgetrocknet waren und die rote Erde zu Tage treten liessen. Ziemlich lebhaftes Vogelleben konzentrierte sich dagegen in den namentlich in der Ebene überall vorhandenen, die Getreidefelder, Feigengärten etc. umschliessenden Dornenhecken. Eine wahre Pein für den Sammler, haben sie das eine Gute, dass sie wenigstens den armen, viel verfolgten Kleinvögeln und welche gefiederte Kreatur gäbe es, die nicht den Nachstellungen des schiesswütigen Griechen ausgesetzt wäre? einen trefflichen Schutz darbieten, nicht nur zur Fortpflanzungszeit, sondern auch auf dem Zuge, zu welcher Zeit sie an manchen Tagen sehr frequentiert sich zeigen. Die kleinen Bewohner dieser noch mit allerlei Gesträuch durchwachsenen, stacheligen und daher absolut unübersteigbaren Opunzienhecken sind im Allgemeinen sehr auf der Hut vor Nachstellungen, was überhaupt von allen in der Nähe der Städte lebenden Arten gilt, mögen sie nun die steinigen Berglehnen oder die fruchtbare Ebene oder gar den spärlich bewachsenen und ausserdem fast beständig von einigen (oft balbwüchsigen!) Vogeljägern abgesuchten Strand bewohnen, und verschwinden gewöhnlich, besonders wenn sie einmal beschossen sind, alsbald in dem Dornengewirr; hat man aber wirklich das Glück, ein Exemplar zu erlegen, so ist damit nun nicht gesagt, dass man auch seiner habhaft wird; nicht tötlich getroffen, entkommt das Opfer gewöhnlich, indem es sich versteckt; aber auch, wenn man es hat fallen sehen und die Stelle genau gemerkt hat, gelingt die Auffindung oft sehr schwer, weil das Pflanzengewirr zu dicht ist oder weil man überhaupt nicht an die Stelle zu kommen vermag. Während nun der einheimische „Jäger", der in diesem Punkt überhaupt keine Sentimentalität kennt, sich nicht lange mit Suchen abgibt und viel lieber auf neue Beute 
lauert, so ist es für den gewissenhaften Sammler, dem sehr daran gelegen ist, das endlich zur Erlegung gebrachte Opfer doch auch in seine Gewalt $\mathrm{zu}$ bekommen, ein äusserst peinliches Gefühl, solche Stücke schliesslich doch verloren zu geben, und man zieht, nachdem man mehrere Male viel Zeit mit vergeblichem Suchen vergeudet, und sich alle möglichen Verwundungen an Körper und Kleidung zugezogen, es unbedingt vor, nur dann zu schiessen, wenn man ganz sicher ist, dass der Vogel auf zugänglichem Terrain herunterfallen muss. Dass bei dieser Art Jagd eine Menge - und gerade vielleicht die wertvollsten - Objekte unbeschossen bleiben, und nicht einmal genau angesprochen werden können, ist klar. Doch gewährt so die Erbeutung von wenigen Stücken bedeutend mehr Befriedigung, als wenn man sich des völlig unnützen Mordens einer ganzen Anzahl bewusst sein muss. -

Der elftägige Aufenthalt in Calamata, leider mehrfach durch schlechtes Wetter beeinträchtigt, sollte noch zu einem Ausfluge in die Vorberge des Taygetos benutzt werden. Diese Tour, welche ich in Begleitung eines zwar nicht ortskundigen, aber doch einigermassen mit der Landessprache vertrauten Landsmannes unternehmen wollte, musste ich schliesslich doch ohne jeden Dolmetscher zur Ausführung bringen; denn als der biedere, stets durstige Sachse durchaus sich nicht einfinden wollte, so ritt ich ohne ihn los - er kam übrigens (zu seiner Ehre sei's gesagt!) am nächsten Tag, als ich schon wieder auf dem Heimweg begriffen war, nach mancherlei Irrfahrten, halb tot vor Ermattung nachgestiegen! und dank der freundschaftlichen Ratschläge und Winke des Herrn H. Zahn, eines Neffen unseres vortrefflichen deutschen Konsuls, ging die Exkursion ohne besondere unangenehme Vorkommnisse, wenn ich von der Bedrohung durch einen rabiaten Revolverhelden, der mir in einem kleinen Bergdorfe gegenüber trat, absehe, ganz vorzüglich von statten. Mein Führer Jani, in den Bergen zu Hause, die ich besuchen wollte, und der Agoiat (Pferdeknecht) waren mir die aufmerksamsten, ergebensten Begleiter, die ich mir wünschen konnte, dabei von einer ausserordentlichen Genügsamkeit, und ich bedauerte nur, dass unsere Unterhaltung auf wenige Sätze beschränkt bleiben musste, und schon aus diesem Grunde ein längerer Aufenthalt im Gebirge untunlich schien. Trotz des wenig freundlichen Wetters - bei Eintritt in das eigentliche Gebirge empfing uns ein allerdings nur kurz währender Schneesturm - , welches auch das Photographieren am ersten Tage ganz unmöglich machte, gewann ich einen recht angenehmen Eindruck von der ziemlich grossartigen Gebirgswelt. Der Blick auf die lachende messenische Landschaft und die blaue Meeresbucht entzückte stets auf das lebhafteste mein Auge, trotzdem er etwas verschleiert war. Von dem hoch oben sich hinziehenden Saumpfade aus präsentierten sich die meist mit niedriger Vegetation begrünten Berge, welche sehr steil in das tiefe Tal abfallen, recht stattlich. Schon bald nach Mittag erreichten wir 
das armselige Bergdorf Ladá, wo in einem äusserst primitiven Chan übernachtet werden sollte. Die Nachmittagsstunden benutzte ich dazu, um ohne Weg und Steg die karstigen Berge abzuklettern, die sich gleich oberhalb der Ortschaft überaus steil erheben. Obschon ich verschiedene Kämme erreichte und auch in die dem Tal abgewandte Seite des Bergrückens Einblick erhielt, so wurde doch meine Hoffnung, hier vielleicht Steinhühner oder andere Felsenbewohner anzutreffen, nicht erfüllt. Auch sonst zeigte sich die Gegend hier oben recht wenig belebt, während die mit reicher Vegetation ausgestattete Talsenkung unterhalb der Ortschaft ziemlich reiches Vogelleben aufwies, das leider nur schwer sich genauer eruieren liess, da in die in Terrassen ansteigenden und durch Hecken getrennten Olivengärten schwer einzudringen war. Mancherlei Meisen, zum 'Teil unbekannte Grasmücken, Buchfinken, Ammern machten sich hier besonders bemerkbar.

In mein kleines „Wirtshaus" zurückgekehrt, wurde ich alsbald der Gegenstand der ausgesuchtesten Aufmerksamkeit; was man mir an den Augen absehen konnte - ich hatte mir sogleich die einzige Dachkammer im 1. Stock als Aufenthaltsort gewählt, von wo aus ich einen Blick auf das malerische Dächergewimmel des steil abfallenden Dorfes hatte und durch die nur mit Holzläden verschlossenen Fenster wenigstens frische Luft kneipen konnte geschah in kürzester Zeit, und auch das mehr als bescheidene Nachtlager auf der Holzbank neben den auf der Erde schlafenden Begleitern wäre trotz der recht empfindlichen Kälte leicht zu ertragen gewesen, hätte nicht die absolute Unmöglichkeit einer Conversation (was nicht hinderte, dass ich doch einem gichtischen Alten meinen ärztlichen Rat erteilen musste) den Aufenthalt zu einem etwas tristen gestaltet. Am nächsten Morgen mit Tagesgrauen ging es weiter den Berg hinan, an einem uralten Bestand von Edelkastanien vorbei, der mit Schwarzkiefernwald bewachsenen und mit Neuschnee bedeckten Passhöhe von Grammeni Petra zu, welche bei $1296 \mathrm{~m}$ nach etwa 2 Stunden erreicht war. Von hier aus bietet sich ein herrlicher Blick auf das weit herab von Schneefirnen glänzende Bergmassiv des Taygetos $(2409 \mathrm{~m})$. Dann senkt sich der Saumpfad abwärts in lichtem Kiefernwald gegen die berühmte Langadaschlucht hin, die mir indessen $\mathrm{zu}$ besuchen leider nicht vergönnt war, da ich die Berghänge etwas absuchen wollte, und da die Tour ohnehin schon durch eine äusserst anstrengende, aber leider vergebliche Pirsche auf einen starken Bussard, der auf einem mindestens $30 \mathrm{~cm}$ hohen Raupengespinst (wie sie die meisten Kieferngipfel krönten) aufgehakt war, starke Verzögerung erlitten hatte. Natürlich war dieser Vogel, wie immer, für einen 'Astós (deren es übrigens in diesem Gebiete $110 \mathrm{ch}$ ziemlich viele geben soll) ausgegeben worden. Nach kurzer Mittagsrast in einem Chan traten wir den Rückweg an und schon am gleichen Abend kurz nach Eintritt der in diesen südlichen 
Ländern merkwürdig rasch hereinbrechenden und kurz währenden Dämmerung hatte mich mein zuverlässiges Maultier, das, ohne je zu straucheln oder zu schwanken, mit nie versagender Sicherheit den schwierigen Weg überaus rasch zurücklegte, wieder wohlbehalten an die Stätte menschlicher Kultur zurückgebracht. -

Die Tage meines Aufenthaltes in Calamata waren nur zu bald $\mathrm{zu}$ Ende und es hiess Abschied nehmen von meinem alten und von den neu gewonnenen Freunden. Am 28. März in aller Frühe verliess ich per Eisenbahn das mir ganz vertraut gewordene Städtchen. Die Trasse führt erst durch die Ebene - gerade begannen sich die Feigenbäume zu begrünen und die Korinthenstöcke zeigten schon ziemlich viel frischen Blätterschmuck nahe dem vogelreichen Sumpfe von Tsepherimini vorbei, angesichts des Berges Ithome aufwärts durch die grosse obere messenische Ebene, dann steiler hinan, schliesslich in schönen Serpentinen zu dem mit Resten von Laubwald bedeckten und mit Steinblöcken übersäten Pass von Makriplagi $(600 \mathrm{~m})$. Von hier an beginnt die Landschaft einen äusserst öden Eindruck zu machen, da nur steinige Berghänge, mit spärlichen noch unbelaubten Bäumen bestanden, und gänzlich gebüschlose, zum Teil angebaute Hochtäler sich dem Blicke darbieten. Das einzige, was bemerkenswert erschien, waren die malerischen Hirtengestalten, in weisse Wollmäntel gehüllt, welche von den Bahnstationen aus in langen Zügen sich den Bergen $\mathrm{zu}$ bewegten. Das Bergland von Arkadien, das ohnehin kaum mit andern gleich gearteten Gebirgen des Balkans (so z. B. des Occupationsgebietes) sich messen kann, ist dadurch, dass es fast ganz des Waldes beraubt ist, aller Romantik bar und mutet so kalt und nüchtern an, dass es grosser Mühe bedarf, sich die mythischen Begebenheiten des Altertums, die vielfach hierher verlegt wurden, in Verbindung gerade mit dieser Landschaft vorzustellen. Die Hauptstadt des Landes, Tripolis, bietet insofern wenigsten eine Abwechselung, als ihre Gärten mit einigen Gebüschgruppen und kleinen Cypressenhainen geschmückt erscheinen. Das Gefühl der Einsamkeit und trostloser Verlassenheit schwindet erst, wenn die Bahn sich weiter hinab in's gebüschreiche T'al gesenkt und endlich bei Myli wieder das Gestade des Meeres (Golf von Nauplia) erreicht hat. Von Vögeln war auf der ganzen Fahrt bis hierher herzlich wenig $\mathrm{zu}$ bemerken. Häufig zeigte sich nur die Elster, sogar im Hochtal von Frankowrysis, einzeln der Kolkrabe; ein grosser $\mathrm{F}$ alke liess sich mit angelegten Flügeln relativ langsam in das Tal herabsinken und hakte auf einen Felsen auf; einige Passer domesticus, Hirundo rustica und Galerida kamen ferner zur Beobachtung.

Freundlicher gestaltete sich das Bild bei der Fahrt durch die Ebene von Argos, die Turmfalken und Steppenweihe n belebten. Hierauf steigt die Bahn abermals an und erklimmt langsam über steinige Karstberge den öden Pass von Dherwenaki, 
um sich abermals zu senken und zuletzt durch lichten Strandkieferwald bei Korinth an das Meer heran zu treten. Dann ging es weiter über den hochinteressanten Kanal, der kirchturmtief eingeschnitten den Isthmus durchquert und an dessen Wänden sich einige wohl erst kurz angekommene Rötelfalken tummelten, den Nordrand des saronischen Meerbusens entlang, wo sich von der Bahn aus, welche an buntschimmernden Felswänden hoch über dem blauen Meere und über den grünen Gipfeln der Aleppokiefern-Wälder hinführt, dem erstaunten Auge Blicke entrollen, wie sie auch an den Gestaden der italienischen Riviera nicht prächtiger gedacht werden können. Abends $7 \frac{1}{2}$ Uhr, nach fast 14-stündiger Fahrt, langte ich endlich in Athen an, wo ich im Hôtel Minerva sehr gute Unterkunft fand. Mein kurz bemessener Aufenthalt in dieser Stadt wurde leider durch einen äusserst starken und rauhen Wind, der riesige Staubwolken durch die Strassen fegte, beeinträchtigt, sodass selbst das Verweilen auf der köstlichen Akropolis, trotz des wunderhar blauen Himmels, nicht sonderlich angenehm genannt werden konnte. Einige hoch über den Felsen kreisende Kolkraben und die Beobachtung von Steinsperlingen, die gerade im Mauerwerk über der Eingangssäulenhalle des Parthenon ihr Wesen trieben, liessen über allem Kunstenthusiasmus auch das ornithologische Moment nicht ganz zu kurz kommen. In letzterer Hinsicht aber bildete den Höhepunkt meines Aufenthaltes in der griechischen Hauptstadt der Besuch bei unserm Landsmanne Dr. Theodor Krüper, der mich in liebenswürdigster Weise empfing und aus dem reichen Schatze seiner Erfahrung so viele wertvolle Winke und Aufschlüsse erteilte, dass ich nur immer wieder die kurze Dauer meines Aufenthaltes in diesem Lande beklagen musste. Am nächsten Morgen bestellten wir uns zusammen ins Universitätsmuseum, in das ich mir schon am Tage vorher nach vielen vergeblichen Umherfragen Eintritt verschafft hatte, und es war mir ein grosser Genuss, nun von so kundiger Seite die Schätze desselben noch einmal vorgeführt zu erhalten. Leider war meine Zeit bemessen, denn wir wollten noch dem ziemlich entfernt gelegenen Hause des Universitätspräparators Stavros Strimenéas einen Besuch abstatten, um dort eine von seinem Sohne in vergangenem Herbste in Epirus zusammen gebrachte Sammlung von Vogelbälgen zu besichtigen. Nachdem ich mir einiges ausgewählt und auch nach griechischer Sitte einen Begrüssungs-Schnaps entgegengenommen hatte, musste ich in's Hôtel eilen, um die Abreise zu betätigen. Aber Dr. Krüper wollte es sich durchaus nicht nehmen lassen, mich dahin zu begleiten, und lief mit seinen 75 Jahren so behend neben mir her, dass ich mir nachher Vorwürfe machte, es könnte ihm der Eilmarsch übel bekommen sein. Möge der hochverdiente liebenswürdige Forscher sich noch lange Jahre einer solchen wirklich exceptionellen Rüstigkeit erfreuen! Das wünschen mit mir wohl alle die Freunde in seiner alten Heimat. 
Um die Mittagszeit des 31. März verliess der Eisenbahnzug die griechische Hauptstadt. Regendrohende Wolken, welche das ganze Firmament umschleierten und sogar die nahe Inseln Salamis nur in ihren Umrissen erkennen liessen, beeinträchtigten den Genuss, den sonst die ganze Fahrt geboten haben würde, einigermassen. Recht lieblichen Anblick müsste die vegetationsreiche, überaus fruchtbare Küste am Nordrand des korinthischen Meerbusens bei hellem Sonnenschein oder im Lichte der abendlichen Beleuchtung gewährt haben. Als der Zug die Gefilde von Achaia durcheilte, entlud sich ein schweres Gewitter über uns. An Kleinvögeln schien namentlich zwischen Korinth u. Patras kein Mangel.

Auch die Tage, welche ich in Patras bis zur Abfahrt meines Dampfers verbrachte, hatten unter der Ungunst der Witterung zu leiden, da, um diese Jahreszeit ganz ungewöhnlich, häufig Regengüsse, ja förmliche Landregen sich einstellten. Ich wollte vor allem nach dem südlichen Akarnanien einen Abstecher machen, aber meine Hoffnung, unter den ziemlich zahlreich in Patras lebenden Landsleuten einen der Landessprache kundigen Begleiter zu finden, erfüllte sich nicht, trotzdem unser Osterfest vor der'Türe stand, das gewiss manchen zu Ausflügen animierte. Herr Konsul Hamburger, den ich in dieser Sache aufsuchte, weil seine Angestellten grösstenteils Deutsche sind, wusste keinen andern Rat, als mich auf die natürlich in keiner Weise in Frage kommenden Hôtelkuriere zu verweisen. So entschloss ich mich denn, allein zu reisen. Man hatte mir verraten, dass in Agrinion ein deutscher Lehrer ansässig sei, welcher, selbst für ornithologische Dinge interessiert, mir jedenfalls gerne behilflich sein würde. So schiffte ich mich denn in der Frühe des 2. April auf dem kleinen Dampfer ein, um bei herrlichstem Wetter über den Golf von Patras nach dem am Fusse des mächtig aufragenden Varassowo gelegenen Kryoneri überzusetzen. Dort ging es in die Eisenbahn und bald tauchten die weiten Lagunen von Missolungi auf, welche indessen von Vögeln, soweit sich das von Zuge aus feststellen liess, sehr wenig belebt waren. Von hier ging es weiter nach Ätolikon, das auf einer Landzunge mitten in der Lagune liegt, und dann durch ein sehr anziehendes mit üppigem Ölbaumwald, später mit Buschwald und schliesslich, nachdem die Trasse sich wieder gesenkt, mit hochstämmigen Sumpfwald bestandenes Gelände, in die weite Talebene von Agrinion. Zahlreiche Raubvögel verschiedener Art, vom hoch in dem blauen Äther sich wiegenden Gänsegeier bis herab zum Turmfalken belebten die Gegend und kaum konnte ich es erwarten, bis der Zug endlich zum letztenmale hielt. A ber eine grosse Enttäuschung harrte meiner, indem man mir gleich am Bahnhof sagte, dass der gesuchte Landsmann nach Missolungi verreist (oder verzogen?) sei. So konnte ich nichts besseres tun, als mich einem „Xenodochos" anzuvertrauen, dem ich meine Wünsche, so gut es eben gehen wollte, zu erkennen gab; er brachte mich in sein höchst 
zweifelhaftes "Hôtel" und führte mich in ein Speisehaus, wo ich vorläufig mir selbst überlassen blieb. Am Nachmittag wollte ich doch die beabsichtigte Tour nach dem Wrachori-See zur Ausführung bringen; mein Führer, ein äusserst ungesund aussehender, verschmitzt dreinschauender, aber doch williger, junger Mensch von 18 Jahren brachte mich auch wirklich an's Ziel. In einer Lücke des den ganzen See umgebenden Waldes, dessen Stämme, uralte Weiden und hochstämmige Silberpappeln ringsum von Wasser umflutet waren, fand sich eine äusserst malerische Fischeransiedelung und bald sassen wir in einem flachen Boot, das ein älterer gutıütig dreinschauender Mann ruderte. Bevor ich noch meinen Drilling geladen, konnte ich es mir nicht versagen, die malerisch am Ufer gruppierte Familie der Fischer und das eigentümliche Bild der zur Hälfte im Wasser stehenden Weidenstämme auf die photographische Platte zu bannen, als auch schon ein mächtiger Seeadler, der sich wohl auch den Ankömmling besehen wollte, gerade über uns, keine $30 \mathrm{~m}$ hoch, schwebte. In grösster Eile griff ich nach dem Gewehr und schob die $\mathrm{Pa}$ tronen ein, aber der in solcher Eile auf den nun schon entfernter fliegenden Raubvogel abgegebene Kugelschuss verfehlte sein Ziel. Das war ein schlechter Anfang, aber ähnlich erging es leider auch mit den nachher auf in rascher Folge neben uns auftauchende Rohrweihen; Rallenreiher, Löffelenten, Seeschwalben und manche andere Vögel abgegebenen Schrotschüssen, die fast alle fehlgingen, da der See solche Wellen warf, dass an ein nur halbwegs sicheres Abkommen unmöglich zu denken war. So musste ich mich denn auf die Beobachtung beschränken und diese war mir immerhin wertvoll genug, hatte ich doch alsbald nach kurzer Fahrt auf einer aus dem Wasser mächtig aufragenden Silberpappel den Horst des Seeadlers entdeckt, bei welchem fortwährend ein alter Vogel Wache hielt, während der 2. über dem See auf und abstrich und bei dieser Gelegenheit noch einmal, allerdings wieder vergeblich, beschossen werden konnte. Da ein Durchbrechen des dürren Schilfgürtels und ein Eindringen in den mit dichtem Unterwuchs bewachsenen Sumpfwald ohne besondere Vorbereitungen nicht $\mathrm{zu}$ ermöglichen war, musste ich mich darauf beschränken, mit dem Jagdglas bewaffnet mir das schwankende Bild aus der Ferne möglichst fest einzuprägen und einige photographische Aufnahmen zu machen, die indessen ebenfalls keine scharfen Bilder ergaben. Dann ging es langsam zurück nach dem kleinen Hafen der Fischer. Auch die Versuche, vom Lande aus mich dem geheimnisvollen Walde zu nähern, waren leider vergeblich, da ein grundloser Morast den See umgab. So traten wir über kurzgrasige, steppenartige Wiesen, dann und wann an den Hütten nomadisierender Schafhirten vorbei, die mir einen köstlichen Trunk von frisch gemolkener Milch darboten, den Rückweg an und langten erst nach Eintritt der Dunkelheit in Agrinion an. Am nächsten Tage wollte ich den Rückweg 
auf anderer Route antreten und zwar durch die Felsenschlucht der Klissura die Bahn bei Ätolikon wieder erreichen, und es galt, für diese ziemlich anstrengende Tour ein Maultier zu mieten. Nach längeren Bemühungen, bei denen mich mein Wirt im ganzen Städtchen herumführte, liess sich ein Pferdebesitzer herbei, für den nächsten Morgen einen Maulesel zur Verfügung zu stellen. Wer aber nicht kam, das war der betreffende Agoiat. Nun hiess es abermals auf die Suche gehen; aber da es inzwischen zu regnen angefangen hatte - der Grieche ist äusserst wasserscheu -, wollte durchaus niemand von den ohnedies wenig freundlich dreinschauenden Anatoliern ein Reittier oder einen Wagen hergeben, und ich war schliesslich herzlich froh, als nach langen Verhandlungen endlich ein etwa 10 jähriger Junge mit einem Maulesel erschien. Mit grosser Verspätung ritt ich endlich ab in den immer heftiger werdenden Regen hinein. Dass der Sattel keine Steigbügel hatte, dass der Junge zu schwach sein würde, mich beim Wiederbesteigen des Tieres zu unterstützen, und dass ich bald dem nur dürftig bekleideten, barfüssigen Begleiter die Decke, auf der ich sass, abtreten musste, genierte mich wenig, war ich doch der festen Überzeugung, dass das Wetter sich wieder bessern würde. Ich war schon 2 Stunden geritten, hatte einige Vögel vom Sattel aus erlegt, und auch ein kleines Abenteuer mit meinen Grautier, das vor einer geschossenen Saatkrähe, als sie am Sattel befestigt werden sollte, die Flucht ergriff und mich abzuwerfen drohte, glücklich überstanden, und ich befand mich erst auf dem Strassendamm, der zwischen den Seen von Angelokastro und Wrachori durch prächtig üppigen Sumpfwald hindurch schneidet, aber anstatt nachzulassen, wurde der Regen immer stärker, es schüttete wie mit Kübeln, so dass an ein Sammeln nicht mehr zu denken war und ich beschloss, den Weg zu Fuss fortzusetzen. Endlich erreichten wir einen kleinen Chan; die Aufnahme war die denkbar unfreundlichste, und schliesslich stellte sich heraus, dass der Junge nicht mehr weiter wollte. Erst nach energischen Vorstellungen und nachdem ich mir die Begleitung eines schwer bewaffneten Gensdarmen, der die Passage der Klissura für einen einzelnen Fremden wegen der zahlreichen Wegelagerer (!) für ein Ding der Unmöglichkeit erklärte, schliesslich hatte aufdrängen lassen, nur um meinen Eselsjungen wieder auf die Beine resp. in den Sattel zu bringen, konnte der Weitermarsch angetreten werden. Natürlich ohne jede Fährlichkeit, nur jämmerlich durchnässt und durch das zeitweise vollständige Zurückbleiben des aus bereits durchweichten Effekten und $\mathrm{Pa}-$ tronen bestehenden Gepäcks geängstigt, passierte ich den grossartigen Engpass, der mir sicher unter andern Umständen viele Gelegenheit $\mathrm{zu}$ schönen Beobachtungen gegeben haben würde (wenn ich auch nicht gerade auf die hier horstende Aquila bonellii rechnen durfte), und war froh, nachdem ich mit meinem aufgedrungenen Beschützer über den verlangten „Bagschisch“ einig 
geworden, allein weiter patschen zu können und endlich nach Durchwatung diverser fusstiefer Wasserlachen, die die Strasse überschwemmten, Ätolikon zu erreichen. In der Nähe dieses Ortes entschädigte mich der Anblick eines über der Lagune hinstreichenden Seeadlers etwas für den gehabten Verdruss; ausser grossen Dohlen- und Satkrähen-Flügen, die unter diesen Umständen unbeschossen bleiben mussten, waren auf dem ganzen Marsche nur ganz vereinzelte Konstatierungen zu machen. Die Stunden, die ich hier, bis auf die Haut durchnässt, im kalten Wartesälchen verbrachte, bis mich endlich der Bahnzug aufnahm, und ebenso die schwierige Einschiffung und die bei stürmischen nasskalten Wetter auf dem Verdeck des Dampfers bewerkstelligte nächtliche Überfahrt über den Golf von Patras werden mir als Abschluss dieser Osterpartie wohl stets in nicht sehr angenehmer Erinnerung verbleiben.

Nach einem Ruhetage, den ich zu Spaziergängen und photographischen Aufnahmen der malerisch sich aufbauenden Stadt und der den Hintergrund bildenden ziemlich weit herab beschneiten Berge benutzte, sollte doch noch eine Jagdexkursion an die elische Küste bei Monolada unternommen werden. Eine ziemlich lange Eisenbahnfahrt, dann ein langer Marsch bei drückender Sonnenhitze durch die zuerst fruchtbare, schliesslich nur mit Steppenpflanzen und Dorngestrüppen, namentlich Pistacienbüschen bewachsene Ebene und entlang dem Strande bis zum grossen Brackwassersee von Monolada und wieder zurück auf dem gleichen Wege, sie wogen die aufgewandte Zeit und Mühe kaum auf, so interessant es mir auch war, ein neues Landschaftsbild kennen zu lernen. Dank der Vermittlung eines Krämers, an den ich empfohlen war, hatte sich diesmal wenigstens das unangenehme Geschäft, einen ortskundigen Führer zu finden, der mir bald in Gestalt eines einarmigen Alten zur Verfügung stand, rasch abgewickelt, und ich gelangte in verhältnismässig kurzer Zeit, da es nur wenig zu sammeln gab, an mein Ziel. In den Brackwassertümpeln hinter der niederen Düne, an denen dann und wann malerische Gruppen von Aleppokiefern eine angenehme Abwechslung und etwas Schatten boten, zeigten sich nur Schildkröten (Testudo graeca) häufig, von denen ich denn auch in Ermangelung eines Besseren 4 kapitale Exemplare und ein junges Tier im Rucksack verschwinden liess, um sie lebend den Münchener Herpetologen mitzubringen. Viele Elstern, einige Sammetköpfchen, da, wo das Dornenwachstum durch Zwiebelgewächse abgelöst wird, diverse Cettisänger, ein auf der Wanderschaft begriffenes Rotkelchen, wenige Haubenlerchen, ein nicht näher identifizierter Rohrsänger, das war die ganze Vogelwelt, die in dem Küstengelände sich bemerkbar machte. Ziemlich reges Vogelleben aber zeigte sich auf dem nur durch die Düne vom Meere getrennten Brackwassersee; wohl einige 100 Enten, unter denen nur Löffel- und Spiessente zu erkennen waren, auch 
ein grösserer gansartiger Vogel, den ich nicht ansprechen konnte, graue Reiher, einige junge Silbermöwen, und eine Seeschwalbe, an Strandvögeln diverse Wasserläufer, Uferläufer, und ein grosser Regenpfeifer, wie es schien, Squatarola, und ziemlich sicher 2 Brachschwalben (Glareola), alle diese Vögel waren so scheu, dass an ein genaues Beobachten oder gar schussgerechtes Anpirschen nicht $\mathrm{zu}$ denken war. Um den Abendzug noch zu erreichen, der mich nach der Stadt zurückbringen sollte, musste ich nur zu früh wieder den Rückweg antreten. Gerne hätte ich noch den ausgedehnten Eichenbeständen, die sich von der Grenze von Elis bis nach Achaia hinein erstrecken einen Besuch abgestattet, aber der Tag der Heimfahrt der 6. April, war heran gekommen, und da es unbestimmt war, wann der von Athen kommende Dampfer abfahren würde, konnte ich mich nicht mehr weit von der Stadt entfernen. Nach herzlicher Verabschiedung von Freund Lalios, der mir auch diesmal wieder mit Rat und Tat beigestanden hatte, dampfte ich gegen Mitternacht erst - es war wieder der "Samos," dessen Kapitän, der alte Seebär Demetrios schon auf der Herfahrt mein Freund geworden war -- aus dem Hafen von Patras; bereits am Nach mittag des 7. nach prächtiger Fahrt legten wir in Korfu an und nach kurzem Aufenthalt, den ich zur Besichtigung der interessanten Stadt verwandte, ging es wieder in See. Nur wenige Graumantelmöwen tummelten sich in der Bucht. Am nächsten Tage zeigte sich, abgesehen von 2 Möwen nicht ein Vogel beim Schiffe. Früh morgens am 9. April beobachtete ich einen finkenartigen Vogel, der genau nach Osten bei entgegenstehendem Winde sich dem fernen Lande zuwandte; sonst flog nichts über der See, die ruhig wie ein Spiegel dalag. Interessanter war es deshalb, das Leben an Bord $\mathrm{zu}$ beobachten, das heute insoferne eine Abwechselung bot, als mit dem Schlage 11 Uhr Vormittag unter Glockengeläute und Schlachtung zweier Schafe, eines Mutterschafes und eines Lämmchens, das griechische Osterfest seinen Anfang nahm. Abends gegen $7 \mathrm{Uhr}$, als wir schon eine zeitlang neben der istrischen Küste hingefahren waren, war wieder einiges Vogelleben zu konstatieren. Ziemlich viele weissbäuchige Sturmtaucher, einzeln und in Gesellschaften von 3-12 Stück, zogen dicht über das Meer hin gegen Westen; etwas später bewegte sich ein Zug ganz kleiner Enten - wohl Anas crecca - in gleicher Richtung vorbei. Lange hielt ich mich an diesem herrlichen Abend auf der Kommandobrücke auf und lauschte dem leisen Gurgeln der Wasser und den nicht minder eintönigen frommen Gesängen und Gesprächen, mit welchen sich der Kapitän und seine Leute, in froher Voraussicht der am Ende der langen Fastenzeit zu erwartenden materiellen Genüsse, die Zeit bis zur Auferstehungsfeier um Mitternacht vertrieben.

Am nächsten Morgen wurde es fast $10 \mathrm{Uhr}$, bis wir endlich den Dampfer in Triest verlassen konnten. Die Stunden bis zur 
Abfahrt des Abendschnellzugs, mit dem ich am nächsten Nachmittag wieder in München anlangte, liessen sich ebenso belehrend wie angenehm durch Besichtigung des ziemlich reichhaltigen, namentlich ansehnliche Serien von Vertretern der Avifauna adriatica ${ }^{1}$ ) aufweisenden, städtischen Ferdinand-Maximilian-Museums und durch einen Besuch von Park und Schloss Miramar ausfüllen, sodass die Reise, die mir infolge des meist überaus freundlichen Entgegenkommens der Griechen nur in angenehmster Erinnerung bleiben wird, auch in dieser Hinsicht einen guten Abschluss fand. -

Ich komme nun zur Aufführung der speciellen Sammlungsund Beobachtungsergebnisse. Es mag bei dieser Gelegenheit angebracht erscheinen, auch eine kleine von der epirischen Küste (Hag Saranti), also aus nunmehr türkischem Gebiete stammende, Balgkollektion mit zu berücksichtigen. -

Ohne auf Körpermessungen allzuviel Gewicht legen zu wollen, habe ich es doch in zahlreichen Fällen für zweckmässig befunden, inier die hauptsächlichsten Masse, unter welchen namentlich die bei gleichaltrigen und gleichgeschlechtigen Vögeln auffallend konstante Flügellänge in Betracht $\mathrm{zu}$ kommen hat, ausführlicher wieder zu geben. Wenn ich mir auch gewiss nicht verhehle, dass bei den oft sehr difficilen Messungen an kleinen Objekten eine Summe von Fehlern unterlaufen können, so wird man mir doch auch darin Recht geben, dass der Vergleichung von Messungsresultaten, welche von einer und derselben Person stammen, stets ein weit grösserer Wert innenwohnen wird, als wenn man genötigt ist, die Ergebnisse verschiedener Forscher einander gegenüber zu stellen. Deshalb nahm ich auch keinen Anstand, hier mit verhältnismässig kleinen Vergleichsserien, wenn sie auch von mancher Seite eine etwas geringschätzige Beurteilung erfahren sollten, hervor zu treten.

Der korrekteste Messungsmodus scheint mir der zu sein, bei der Eruierung des Schwanzmasses den Stab oben anzulegen; um die Schnabellänge zu erhalten, setze ich die Zirkelspitze stets auf der Grenze zwischen Stirn und Schnabelgrund ein oder, wenn sich beide nicht deutlich gegen einander absetzen, am hintersten Ende der Schnabelbedeckung. Ausser den allgemein gebräuchlichen Abkürzungen für Flügel-, Schwanz- und Schnabellänge kommt noch dann und wann eine solche für die Länge der Hinterzehenkralle $=\mathrm{Kr}$. in Anwendung. Mus. mon. bedeutet Münchener Staatssammlung, Coll. P. = meine Privatsammlung, H. v. L. $=$ Herzog von Leuchtenberg.

1) Ich notierte mir unter anderem 12 Xema minutum, 7 Tinnunculus vespertinus, 6 T. naumanni, 4 Circus macrurus, 12 Hydrochelidon nigra, 16 Alca torda. (Der Verfasser.)

Journ. f. Orn. LUI. Jahrg. Juli 1905. 


\section{Gyps fulvus (Gm.)}

Diese Art kam mir nur in der Umgegend von Agrinion einmal, hoch in der Luft kreisend, zu Gesicht. Einige Zeit vorher hatte ein in Patras ansässiger Deutscher ein Exemplar in der Gegend von Kryoneri erlegt und es einfach liegen lassen. -

\section{Neophron percnopterus (L.)}

Am 30. März beobachtete ich von der Akropolis aus ein Exemplar, welches vom Hymettus her in der Richtung nach dem Piraeus flog. Die Art dürfte in diesen Tagen erst aus dem Süden zurückgekehrt sein. Ein am 2. April in der Gegend von Angelocastro (Akarnanien) in riesiger Höbe kreisendes Geierpaar musste ich ebenfalls als zu Neophron gehörig ansprechen. In der Gegend von Agrinion, wo die ausgedehnten Sumpfwälder mit ihren alten Eichen, Erlen und Silberpappeln, wie auch das nahe Gebirge genügend Horstplätze gewähren, sah ich ziemlich zahlreiche und verschieden grosse Raubvögel; in der Mehrzahl der Fälle war aber die Erscheinung zu vorübergehend, als das eine genaue Bestimmung möglich gewesen wäre.

\section{Circus aeruginosus (L.)}

Zwei alte Weibchen beobachtete ich am 2. April über dem Vrachori-See, ohne dass ich eines zur Strecke bringen konnte.

\section{Circus macrourus (Gm.)}

Die Steppenweihe scheint in den letzten Tagen des März in Griechenland angekommen $\mathrm{zu}$ sein. Am 28. tummelten sich zwei Exemplare über den Weingärten zwischen Myli und Argos. Das erste Exemplar, ein altes Männchen in ziemlich abgenütztem Kleingefieder und mit sehr defekten Schwingen (die linkseitigen Primären waren wie von Motten zernagt und wiesen teilweise nur den kahlen Schaft noch auf) gelangte am 31. März am Naturalienkabinett in Athen zur Einlieferung, als ich gerade dort weilte. Ich erwarb es für meine Sammlung. Die düstergraue Oberseite, namentlich der Hinterkopf, sind stark mit Braun untermischt, die Unterseite vollständig bläulichweiss; während die obersten Stossfedern einfarbig bräunlichgrau erscheinen, zeigen die übrigen eine deutliche, unregelmässige Bänderung; die äussersten Stossfedern sind überwiegend weiss mit graubraunen, schmalen longitudinalen Bändern, resp. rudimentären Bandflecken. Die Oberstossdecken sind bläulichgrau, in der Tiefe aber finden sich auch weissgebänderte Federn. Die Messung ergab folgendes Resultat:

a. 333 ; c. 223 ; t. 63,5 .

Am 2. April traf ich auf den Brachwiesen bei Agrinion eine mit Ausnahme der schwarzen Flügelspitzen vollständig graulich- 
weisse Weihe, welche ich ebenfalls für ein altes Männchen der Steppenweihe halten musste. Sie liess sich wiederholt auf der Erde nieder und schien mit dem Insektenfang beschäftigt; anfänglich sehr wenig scheu, so dass ich mich auf ca. 60 Schritte zu nähern vermochte, wurde sie nach einem Fehl-Schusse etwas vorsichtiger; nachher verschwand sie mitten in einem Saatfeld vor meinen Augen, erhob sich aber bei meiner Annäherung so plötzlich, dass ich nicht zu Schuss kommen konnte.

\section{Circus cyaneus (L.)}

Jedenfalls als Wintergast zu betrachten ist ein am 17. Dezember 1903 bei Hag Saranti (Epirus) erlegtes Männchen. Kinn, Kehle und Kropf sind bei ihm zart bläulichgrau, Rücken und Flügeldecken dunkel rauchbraun, die langen Oberschwanzdecken rein weiss, die kürzeren grau. Der graue Kopf weist spärliche braunschwärzliche Schaftung auf. Die ganz weissen äusseren Stossfedern sind am Ende der Aussenfahne graubräunlich und zeigen sonst nur Reste einer solchen Bänderung.

Die Masse sind folgende:
a. 329 ;
c. 227 ; t. 68,5 ;

\section{Falco eleonorae Gené.}

Ein im Privatbesitz befindliches ausgestopftes Exemplar notierte ich mir in Calamata.

\section{Tinnunculus tinnunculus (L.)}

Der Turmfalk scheint im Peloponnes nicht selten zu sein, wenigstens beobachtete ich ihn wiederholt vom Eisenbahnzug aus, so zwischen Patras und Kyparissia zweimal, dann mehrere zwischen Myli und Argos; bei Calamata begegnete er mir nur auf einem Ausfluge nach Nissi. Ein von dort erhaltenes adultes Männchen, am 23. Mai bei Alagonia (im Gebirge) erlegt, zeigt die Schwingen ziemlich stark verbleicht, die Unterseite relativ gross und dicht gefleckt resp. gestreift, den Kopf unrein gefärbt, die schwarze Schwanzbinde ist breit und auch die Rückenfleckung ist etwas grösser, als das bei unsern Exemplaren gewöhnlich ist. Die Flügellänge beträgt 235 , die Schwanzlänge $180 \mathrm{~mm}$; der Schnabel ist im Bogen gemessen 16,5 mm lang.

Am 2. April traf ich die Art auch zwischen Missolungi und Agrinion mehrfach.

\section{Tinnunculus naumanni (Fleisch.)}

Am 28. März wurde das erste Exemplar von einem Jagdfreund bei Patras geschossen. Am gleichen Tage bemerkte ich einige Exemplare an den Wänden des Kanals von Korinth. Im 
Museum zu Athen kamen die ersten Vögel aus Attika am 31. März zur Einlieferung. Mit der Lebensweise der reizenden Vögel wurde ich einige Tage später in Akarnanien bekannt, wo die Art sehr häufig vertreten ist. In Agrinion tummelten sich nicht weniger als 12 Stück gleichzeitig vor meinem Fenster, indem sie beständig zwischen den Häusern, die zahlreiche Mauerlöcher aufwiesen, hin und her flogen und mit einander spielten, dabei ein entfernt an das Schnarren von Turdus viscivorus erinnerndes Geschrei ausstossend. Dann und wann hakte einer auf einer alten Cypresse auf; sie waren aber ganz unbekümmert um das rege Leben und Treiben auf den Strassen der Stadt und schienen, wie ich zu meiner Befriedigung konstatieren konnte, sich hier absoluter Schonung $\mathrm{zu}$ erfreuen. Der Flug, ein beständiges sehr rasches und daher flaches Flügelschlagen, auf welches ein küızeres oder längeres Schweben folgt, je nach dem, ob der Vogel einem bestimmten Ziel zufliegt oder nur spielend sich bewegt, erinnerte mich etwas an den der Taube; die Flügel scheinen mir etwas mehr gewölbt getragen $\mathrm{zu}$ werden und machen einen kürzeren Eindruck als beim Turmfalken. In einer ganz kleinen Ortschaft traf ich 2 Paare an; ein dicht am Wege auf einem Baum sitzendes Männchen war so ganz in seine Federtoilette vertieft, dass es auf unser Vorübergehen gar nicht achtete; nur ungern kehrte ich zurück und zerstörte das reizende Idyll. Einige Paare bewohnten auch das Dorf Manolada in Elis.

Die Flügel-Masse von 5 in meinem Besitze befindlichen Exemplaren sind folgende:
1) o, ad. Athen 31. III. 04. a :230;
2) " " " " " $"$ a: 226 ;
3) " " Agrinion 2. IV. 04. a:225;
4) " Dachau 1. V. 01. a:232;
5) $\$$, Athen 31. III. 04. a: 235 .

Es ist zu bemerken, dass der Rücken am kräftigsten, fast braunrot, gefärbt erscheint bei dem Vogel von Agrinion; ein ähnliches Kolorit, aber etwas heller und daher lebhafter aussehend, zeigt No. 1; trüb ziegelrot präsentiert sich die Oberseite bei No. 2 u. 5, während Vogel 1 hier einen bläulichen Anflug aufweist und daher einen dunkleren Eindruck macht. Bezüglich der Unterseite fällt auf, dass sowohl der Grundton, wie der Grad der Fleckung, einer ziemlichen Variation unterworfen zu sein scheint. So ist die Unterseite bei Vogel 2) sehr gering gefleckt, denn sie weist in der Mitte nur 2 rudimentäre Flecke und an den Seiten je ca 12 Flecke auf. Diese sind bei dem überhaupt stärker gefleckten Vogel 1) auch grösser. Zerstreute, mässig reiche Fleckung zeigt die Unterseite des bayerischen Vogels; ähnliche Verhältnisse finden sich bei dem Männchen von Agrinion, welches auch den Kropf am intensivsten roströtlich gefärbt hat, während von dem sonst gewöhnlichen rosafarbigen Anflug kaum etwas zu sehen ist. Die beiden männlichen Exemplare aus Attika 
unterscheiden sich noch dadurch, dass die Grundfarbe der Unterseite bei dem 2. eine lebhaftere genannt werden muss, trotzdem Stoss und Schwingen bei ihm etwas mehr verbleicht und abgestossen erscheinen. Ziemlich stark abgeblasst sind die Flügelfedern auch bei No. 3. - Der weibliche Vogel lässt zwei noch nicht ganz ausgewachsene frische Stossfedern erkennen.

\section{Astur brevipes Sev.}

Während meines kurzen Aufenthaltes gelang es mir, nur ein Exemplar dieses interessanten Raubvogels in meinen Besitz zu bringen. Dasselbe soll (was auffallend genug erscheint) am 17. Januar des Jahres bei Calamata erlegt sein. Wenn es auch im „Neuen Naumann" ganz allgemein heisst, die Art komme in Europa erst Anfangs Mai an und ziehe schon Ende August wieder südöstlich ab, dürfte ihre Überwinterung im südlichsten Griechenland doch nicht zu den Unmöglichkeiten gehören, konnte doch S s o mow einige überwinternde in der Krim nachweisen; die Annahme Severzow's, dass der Vogel in Südrussland überhaupt als Standvogel zu betrachten sei, dürfte sich aber kaum bestätigen. Vergleicht man die geradezu klassischen $\mathrm{N}$ a u m a n n'schen Originalbeschreibungen der Federkleider anderer Raubvögel, so müssen uns die Ausführungen über die verschiedenen Gefiedertrachten bei Astur brevipes in der ueuen Folioausgabe des Werkes durchaus unbefriedigt lassen. Es hätte mindestens eine teilweise Wiedergabe der Untersuchungen von Ssomow stattfinden sollen. Nach allem ist das mir vorliegende Exemplar, das als Weibchen bezeichnet ist, ein jüngerer Vogel im ersten Lebensjahre. Das Flügelmass stimmt mit dem von S somow beim jungen Weibchen gegebenen überein (es sind in diesem Stadium die Flügel noch nicht ganz ausgewachsen, während der Stoss schon seine volle Länge erreicht hat); auch die Tarsuslänge stimmt. Dass die im „Neuen Naumann" bei russischen Vögeln gegebenen Laufmasse unrichtig sind, sei nur nebenbei bemerkt! Die Oberseite meines Vogels ist tief dunkelbraun mit ganz schmalen rostbraunen Enden an den Federn und einem graulich düstern Anflug. Gross ist die Übereinstimmung in diesem Stadium mit der allerdings nicht ganz so dunklen Oberseite des weiblichen Sperbers; das trifft auch hinsichtlich der weissen Partieen in den Tertiären, auf dem Schulterfittich und im Nacken zu. Die Oberseite des Stosses ist dagegen wieder ganz Habicht. Die seitlichen Schwanzfedern weisén 9 braunschwarze Binden auf (sofern man die rudimentäre an der Basis mitrechnet), welche auf den inneren Federn an Breite zunehmen. Auf dem weissen Unterstoss finden sich einige unvollkommene braune Bandflecke; die Hosen erscheinen hellschokoladefarbig gebändert. Die breite Querbänderung des Bauches reicht bis auf die Hinterbrust, hier aber finden sich am Federende dicke Tropfenflecken. Die sehr breite Längsschaftung der Vorderbrust 
ist dunkelbraun; sehr deutlich hebt sich ein braunschwarzer Kehlstreif ab. Der Schnabel zeigt, verglichen mit dem eines allerdings etwas stärkeren, jungen Sperberweibchens, absolut gleiche Gestaltung, aber etwas kleinere Dimensionen. Das vorliegende Exemplar gibt sich natürlich sofort durch seine kurzen Zehen als Zwerghabicht zu erkennen.

Hier noch die Masse:

a. 218 ; c. 172 ; t. 49,5 .

\section{Buteo buteo (L.)}

Den Mäusebussard beobachtete ich wiederholt im Peloponnes, doch vermag ich natürlich nicht $\mathrm{zu}$ sagen, welcher Form die oft sehr stattlich sich präsentierenden Vögel angehörten. Ich notierte mir folgende Orte: Ein Paar über Ladá kreisend (dunkle Unterseite), desgleichen oberhalb Alonaki, unterhalb Grameni Petra ein Stück im Kiefernbestand, über dem Kloster Whelanidiá einer mit defektem Stoss, endlich bei Achladokampos (Arkadien) ein Exemplar.

Später wurde ich auch in die Lage versetzt, einen aus dem Peloponnes stammenden Bussard genauer zu untersuchen. Derselbe, ein Männchen, am 25. Juni bei Alagonia (Gebirge bei Calamata) erlegt, fällt durch seine geringe Grösse auf; es sind allerdings Schwingen und Stoss so wenig ausgewachsen, dass man annehmen muss, einen jungen Vogel aus dem Frühjahr vor sich zu haben, wenngleich Schnabel und Fänge keine Jugendmerkmale mehr an sich tragen. Die Oberseite, den Stoss eingerechnet, dessen Oberdecken hier allerdings besonders schön rostbraun endigen, stimmt absolut niit der Färbung bei unsern Bussarden überein; auffallend ist nur ein starker, besonders bei seitlicher Beleuchtung auftretender purpurvioletter Schimmer, der über alle tiefbraunen T'eile ausgebreitet ist. Ferner ist hervor zu heben der starke rostgelbliche Anflug auf Kropf und Brust, welcher zusammen mit der breiten dunkelbraunen Schaftfleckung an die Färbung des jungen Habichts erinnert; doch kommen ähnliche Exemplare auch hier zu Lande vor; so besitze ich ein ausgewachsenes starkes Weibchen aus Niederbayern vom 27. Juli, das nur wenig blassere Unterseite zeigt, sonst aber meinem jungen Vogel aus Griechenland sehr ähnlich ist. Bauch und Unterschwanzdecken ferner sind bei letzterem trübweiss mit rostfarbigem Anflug und zeigen einzelne braune Schaftfleckenrudimente; die rostbräunlichen Hosen haben braune Schaftung. Die Schwanzbänderung ist nur ganz schwach angedeutet, auf der Unterseite noch am besten $\mathrm{zu}$ erkennen; breitet man jedoch den Stoss auseinander, dann erscheinen auf der Innenseite der Federn ganz deutliche Bänder. Die Kinnfedern zeigen feine braune Schaftstriche. Schliesslich wären noch die weisswolligen Augenlider zu erwähnen. Man möchte nach alledem im Zweifel sein, ob man diesen Vogel, welcher allerdings nach 
der kräftigen Entwicklung der Fänge und des Schnabels (die sich also schon bei dem Jungen im ersten Federkleid zu erkennen gibt) zu urteilen, etwas anderes wie unseren gewöhnlichen Bussard darstellt, als Steppenbussard (Buteo desertorum Daud.) ansprechen darf, oder ob in Griechenland vielleicht doch, wenigstens in gebirgigen Gegenden, auch Buteo buteo vorkommt. Einen stärkeren violetten Schimmer kann man ebenfalls bei deutschen Exemplaren beobachten; dass er bei einem jungen frisch vermausertem Vogel besonders ausgesprochen erscheint, darf weiter nicht Wunder nehmen.

\section{Haliaetus albicilla (L.)}

Von dem am Vrachori-See horstende Paare war schon oben die Rede. Der eine Vogel, wohl das Männchen, hatte einen sehr hellen Kopf, der aus der Ferne fast weiss anzusehen war; auch der weisse Stoss deutete auf das Alter des Exemplares hin. Der auf einer hohen Silberpappel stehende Horst war etwa 6-8 m vom Gipfel entfernt; neben demselben ragte ein dicker Ast nach der Seite hervor, auf welchem der 2. Vogel mit Vorliebe Platz nahm; doch sah ich diesen auch rings um den Rand des Horstes herum laufen oder in dessen Mitte sitzen, denn er war immer nur ganz vorübergehend abwesend. Der anscheinend männliche Vogel flog erst am Rande des See's einigemale auf und ab und hakte dann auf einem dürren Ast einer anderen nicht sehr entfernt stehenden Silberpappel auf, wo er lange sitzen blieb. Von hier abstreichend, überquerte er später den See und verschwand, nochmals beschossen, für kurze Zeit, um dann wieder in der Nähe des Horstes, der gegenwärtig (am 2. April) wohl ein Junges enthielt, $\mathrm{zu}$ erscheinen. Nur einmal vernahm ich die hohe Stimme der stolzen Vögel.

Am nächsten Tag hatte ich die Freude, vor Aetolikon ganz nahe dem Ufer ein altes Exemplar zu beobachten, das bei strömenden Regen im Handumdrehen einen grossen Fisch aus dem Wasser hervor geholt hatte und dann niedrig über die Lagune dahinzog.

\section{Apus melba (L.)}

Male.

Am 2. April beobachtete ich bei Agrinion die Art mehrere

\section{Hirundo rustica $\mathrm{L}$.}

Die Rauchschwalbe kommt in Griechenland reichlich um 1-2 Wochen früher wie bei uns an. Das erste Exemplar sah ich am 15. März in Patras fliegen. In Calamata sollen sie am Tage vorher erschienen sein. Drei einzelne Exemplare beobachtete ich denn auch am ersten Tage meines dortigen Aufenthaltes (17. März). In den nächsten Tagen war wenig von ihnen $\mathrm{zu}$ sehen; am 21. begegneten mir wieder vereinzelte Stücke am Strande, 
doch liess sich die Art um diese Zeit auch schon am Neste blicken. Etwas häufiger, meist paarweise, waren sie am 24. März; ein Paar nahm sogar schon feuchte Erde von der Strasse auf zum Nestbau; 6 Paare trieben sich am 26. März um das Haus eines Bekannten herum, welches mitten in einem Garten wenige Schritt vom Meeresstrand entfernt steht. Merkwürdigerweise waren hier alle Nester unter dem vorspringendem Dach frei angeklebt, allerdings durch ein vertikal gestelltes Brett, das aussen am Dach entlang läuft, etwas geschützt; nur eines war oben anstossend, also mit der Decke verbunden und hatte vorn nur ein breites Schlupfloch, sodass man es hätte für ein Mehlschwalbennest halten können, wäre es nicht ganz aus dem gleichen Material und von unten her in gleicher Weise gebaut gewesen, wie die Nachbarnester. Während so 4 Nester an der Ostfront ganz gut erhalten waren, fanden sich auch an der Süd- und Westseite einige mehr oder weniger demolierte Baue. Schon in Patras war mir ein derartiges frei an die Hauswand angeklebtes Nest aufgefallen, doch scheint diese Bauart nicht direkt eine biologische Eigentümlichkeit aller griechischen Rauchschwalben zu bilden, da ich im Gebirge, in Lada, wo am 22. und 23. des Monats noch keine einzige Schwalbe zu sehen war, ein altes Nest im Innern eines Zimmers notieren konnte, und umgekehrt auch bei uns in Deutschland dann und wann einmal ein Rauchschwalbennest aussen angebracht ist.

Am 26. März war Hirundo rustica auch schon im Innern der Stadt im Konsulatshofe am Brutplatze erschienen; leider versäumte ich hier, mich nach dem Standorte des Nestes zu erkundigen. Am 28. sah ich 2 Paare am Stationsschuppen von Issari, etwa $550 \mathrm{~m}$ ü. M.; das eine baute wieder aussen auf dem Giebelbalken sein Nest. Unter dem Perrondach zu Tripolis fanden sich ebenfalls, an Balken angeklebt und oben am Dach anstehend, vorne aber mit grossen Öffnungen versehen, einige Nester. 2 Rauchschwalben bemerkte ich am gleichen Tage in der Richtung gegen Nauplia. In Athen sah ich 2 Exemplare am 29. des Monats am Hadriansbogen, am nächsten Tage eins auf der Akropolis. 6 weitere über der Stadionstrasse. - Zahlreich war die Art am 31. März am korinthischen Meerbusen, dann traf ich sie einzeln und in kleinen Flügen zwischen Athen und Megara. Am 3. April flogen ziemlich viele über der Lagune von Missolungi; die Art schien auch häufig in Agrinion, besonders aber bei Manolada, wo ich an dem kleinen Bahnhofsgebäude nicht weniger als 11 grossenteils besetzte, an der Aussenmauer angeklebte und oben offene Nester notieren konnte. Die Nestinhaber waren fast immer in der Nähe und trugen ein äusserst munteres und zutrauliches Wesen zur Schau. In Patras war diese Schwalbe jetzt nicht selten eingetroffen; ein in einer Mauerecke unter dem steinernen Balkon eines Hauses angebrachtes Nest gewährte einen eigentümlichen Anblick. Nicht unerwähnt möchte ich lassen, dass in gleicher Weise wie 
in Calamata auch in Korfu die Rauchschwalbe um diese Zeit viel häufiger zu bemerken war, wie die Mehlschwalbe.

Eine am 26. März abends $1 / 26$ Uhr genau a u s Süden über den messenischen Meerbusen daherstreichende und alsbald landeinwärts weiterziehende einzelne Rauchschwalbe war jedenfalls auf der Wanderung begriffen ${ }^{1}$ ); man sieht solche einsam ziehenden Vögel dieser Art auch bei uns zuweilen in den späteren Nachmittagsstunden.

Die in Calamata ansässigen Rauchschwalben schienen im allgemeinen keine besonders stark rötliche Unterseite zu besitzen; es gelang mir, das ,röteste“ Männchen von der Ansiedelung am erwähnten Haus, das mit einem blassbäuchigen Weibchen gepaart schien, zu erlegen.

Dieses bildet nun hinsichtlich der Färbung der Unterseite einen eklatanten Übergang zu Hirundo savignii Steph.; Brust und Bauch sind nämlich ausgesprochen rostbraun, nicht so tief wie bei der aegyptischen Form, aber doch völlig in der gleichen Tongebung. Ob nun dieses Exemplar, das wohl ein besonders alter Vogel ist, wie aus der tief kastanienbraunen Färbung des Kinns und der Stirn hervorgeht, ${ }^{2}$ ) zur Varietät Hirundo rustica pagorum zu rechnen ist, also eine individuelle Aberration darstellt, oder ob es vielleicht doch die Repräsentantin einer auch biologisch

1) In einer Besprechung meiner "Ornithologischen Wahrnehmungen auf einer Fahrt nach Aegypten" (München 1903, b. E. Reinhardt) glaubt Herr Dr. Handmann (Ornithol. Monatsschrift 1904 p. 235) meinen Schluss, dass die zahlreich auf dem Schiffe erschienenen Vögel auf das höchste ermattet waren und hier direkt Zuflucht suchten, als nicht einwandsfrei bezeichnen zu müssen, obschon ich ausdrücklich von der Auffindung todesmatter und eingegangener Eremplare (Uferschwalben, Mehlschwalben, Rauchschwalben u. a.) berichtet hatte. Der Herr Referent scheint demnach meine Schilderung nicht genau gelesen zu haben, denn ich kann nicht annehmen, dass er in die Verlåssigkeit meiner Ausführungen irgend einen Zweifel setzte. Hartert sagt im „Neuen Naumann" ausdrücklich, es sei auffallend, wie viele Schwalben im atlantischen Ozean zu Grunde gingen, und übereinstimmend damit erzählte mir ein Kollege, dass er am 2. Oktober 1901 auf der Fahrt nach Südamerika 2 Breitengrade südlich von Madeira einen Flug Schwalben beobachtet habe, der sich auf dem Schiffe niederliess. lch mőchte daher der Ansicht Dr. H a ndman n's, als ob es sich bei den von ihm selbst beobachteten Schwalben "mehr um ein Umschwärmen des Schiffes ohne zwingenden Grund, als um ein Hilfesuchen handelte," nicht beipflichten, sondern im Gegenteil auch in diesem Falle eine in Folge Nachlassens der Flugkraft direkt nötig gewordene Rettungsaction der Vögel angenommen wissen. -

2) Die stärkere Entwicklung der roten Farbe zeigt sich bei dem griechischen Vogel auch darin, dass die mittleren Flügeldeckfedern nach innen zu rostbraune Enden aufweisen.

(Der Verf.) 
abweichenden $Z$ wischenform ${ }^{1}$ ) ist, lässt sich leider nicht sagen, da ich nur dieses eine Stück in meinen Besitz brachte. Ich möchte mich vorläufig für die erstere Annahme entscheiden, sowohl wegen der an den anderen Vögeln gemachten Beobachtungen, als auch deshalb, weil hier die Flecke auf den Schwanzspiessen trübweiss sind und geradeso ausgedehnt wie bei rustica, während bei der Form savignii diese Flecke mehr oder weniger zusammengeschrumpft und stark verdüstert erscheinen. Wie dem auch sei, so möchte ich jetzt von der in meiner aegyptischen Arbeit ausgesprochenen Anschauung abgehen und die aegyptische Rauchschwalbe nur als eine Unterform von rustica, die ja deswegen doch ganz gut etwas biologisch verschieden sich verhalten kann, aufgefasst wissen.

Die Masse des griechischen Exemplars sind: a. 119; c. 99 ! Ein am 20. Juli 1904 in der Wüste bei Alexandrien erlegtes $\$$ der Hirundo rustica savignii misst dagegen: a. 120; c. 87. Das Flügelmass dieses Vogels ist also etwas bedeutender als dasjenige des s. Zt. von mir selbst gesammelten Vogels.

\section{Chelidonaria urbica (L.)}

Am Nachmittag des 17. März sah ich die ersten 5 Exemplare in Calamata, desgleichen einige am 18., ganz vereinzelte über den Bergen hinter der Stadt am nächsten Tag; der 20. März brachte regnerische Witterung und jetzt schien ein grosser Nachschub angekommen zu sein, denn man konnte oft 10-20 Stück beisammen zählen. Mehrfach kam die Art zur Beobachtung am 24., 25. und 26. März, doch immer vereinzelt, nur einmal 5 Stück zusammen. In Athen war die Stadtschwalbe spärlich zu bemerken. Ein Flug von etwa 50 Stück fiel mir am 3. April am Bahnhof zu Missolungi auf; der zwölfstündige Landregen, verbunden mit einem heftigen und kühlen Südostwind, brachte die Vögel sichtlich in Verlegenheit, sich ihre Nahrung zu verschaffen. Das bewies eine Schwalbe, welche dicht an die Mauer des Stationsgebäudes angedrückt sass.

Nur einzelne Exemplare notierte ich in Manolada $u$. in Korfu.

\section{Hirundo rufula Temm.}

In meiner Sammlung befindet sich ein am 7. Mai 1904 auf den Strophaden erlegtes altes Männchen, dass noch sehr gut er-

1) Tatsächlich erwähnt K rüper die H. rustica orientalis Schleg., „welche nur eine rote Varietăt der Rauchschwalbe ist", als überall mit ihr zugleich vorkommend; dieselbe soll auch in der Umgegend Konstantinopels eine sehr gewöhnliche Varietät derselben sein. Man vergleiche auch seine interessanten Ausführungen im Journ. f. Ornithol. 1860 p. 281 über die Hir. boissonneauti Temm., welche allerdings eine befriedigende Aufklärung nicht bringen.

(Der Verf.) 
haltenes Gefieder trägt und folgende Masse aufweist: a. 118; c. $103 ;$ r. 9 .

\section{Biblis rupestris (Scop.)}

Einzelne Exemplare erkannte ich am 19. und 25. März über den Felsen bei Hag Ilias und Whelanidiá, zwei Klöstern in der Nähe von Calamata.

\section{Clivicola riparia (L.)}

Einige Uferschwalben zeigten sich am 21. und 24. März über dem Strande bezw. an der Landstrasse nach Nissi.

\section{Muscicapa atricapilla L.}

Während meines Aufenthaltes in Griechenland konnte natürlich noch kein Fliegenfänger zur Beobachtung gelangen, wohl aber erhielt ich später 3 Exemplare vorstehender Art, welche im Mai auf den Strophaden gesammelt wurden, also sicher auf dem Durchzug sich befanden. Ich führe hier zunächst die Masse an.

$$
\begin{aligned}
& \text { 1. o ad., 8. V. } 04: \text { a. } 79 ; \text { c. } 56 . \\
& \text { 2. o ad., 4. V. } 04: \text { a. } 78 ; \text { c. } 55 . \\
& \text { 3. o ad., } 7 \text {. V. } 04: \text { a. } 79 ; \text { c. } 57 \text {. }
\end{aligned}
$$

Vollständig vermausert hat nur das letztere Stück; es ist oben bereits ganz schwarz, auch die Schwingen sind fast braunschwarz gefärbt, wiewohl jedenfalls nicht frisch; dabei zeigt aber die Stirngegend nur einige schmale Ansätze eines weissen Flecks. Letzterer erscheint auch bei Ex. 2, das erst auf Kopf und Hinterrücken schwarze, dabei aber braungrau gerandete Federn aufweist, nur angedeutet, in Gestalt zweier weisser Federchen. Nur Spuren einer Frühjahrsmauserung lassen sich bei dem ersten Vogel erkennen, der einen kleinen, aber vollständig ausgebildeten Stirnfleck trägt, sonst aber sich dadurch als ganz alter Vogel charakterisiert, dass an den hinteren Sekundären die weisse Farbe eine Ausdehnung zeigt, die nicht gewöhnlich genannt werden kann. Fast das gleiche Bild, nur nicht ganz so ausgebildet, lieferte der Flügel eines aus Hallein stammenden $\mathrm{ganz}$ alten, mit schönem weissen Stirnfleck geschmückten Männchens im Münchener Museum! Interessant war mir auch der Vergleich mit einem alten Männchen ${ }^{1}$ ) der $\boldsymbol{M}$. atricapilla speculigera de Selys (Tunis, Mai 1899), mit welchem der eben erwähnte griechische Vogel (No. 1) hinsichtlich der Armschwingenzeichnung vollständig identisch ist, während der Stirnfleck, wie gesagt, noch nicht ausgebildet ist; nach dem Männchen von Hallein zu urteilen, würde dieser aber im höheren Alter viel grösser geworden sein, wenn

1) Masse: a. 82 ; c. 66 ; r. 10 ; t. 18 ; 
auch kaum so breit und tief gegen den Zügel herabreichend, wie bei der echten speculigera. ${ }^{1}$ ) Der Strophadenvogel steht der letzteren Form, wie gesagt, sehr nahe, denn bei beiden beginnt der Handschwingenspiegel schon auf der 6. Primäre und die Aussenfahnen der in Frage kommenden 3 hintersten Sekundären ("Tertiären", wie manche sagen) sind ganz weiss; ein längliches schwarzes Fleckchen im weissen Felde, welches der Grieche jederzeit auf der vordersten „Tertiäre" trägt, ist als Rudiment der ursprünglich schwarzen Färbung aufzufassen.

Die Zeichnung der hinteren Sekundären bei $M$. a. speculigera ist die folgende:

I. Ganz weiss, nur ein schwarzer Fleck am Ende der Innenfahne.

II. Ganz weiss, nur der Endsaum der Feder und der Endsaum der Innenfahne weiss.

III. Aussenfahne weiss, Innenfahne schwarz.

Obschon mir aus Bayern und namentlich aus Ungarn eine ganze Suite alter Trauerfliegenschnäpper vorliegt, so kann mit diesem Material leider doch nicht der Frage näher getreten werden, ob hier, ähnlich wie es in Bosnien der Fall zu sein

1) Auch ein altes Männchen, der merkwürdigen Form $M$. atricapilla semitorquata (E. v. Hom.) welche in Griechenland, dann auch in der Türkei, auf der Insel Fao im persischen Golf vereinzelt gefunden und im April 88 von Radde im Kaukasus in allen möglichen Variationen zwischen atricapilla und collaris beobachtet wurde, konnte ich untersuchen, dank der Liebenswürdigkeit des Herrn v. Tschusi. Dasselbe wurde am 11. IV. 1896 in Kumbaschinsk (Kaukasus) erlegt. (Masse: a. 79 ; c. 55 ; r. 10,1 ; t. 16). Die Flügeldecken zeigen mehr Weiss, insbesondere sind auch die mittleren weissgespitzt; das ganze Flügelschild ist aber nicht so ausgedehnt wie bei speculigera, indem das Schwarz auf der 3. "Tertiăre“ dentlich auf die Aussenfahne übergreift. Während aber die Schwanzzeichnung von speculigera und atricapilla identisch ist, tritt die schwarze Farbe bei semitorquata mehr zurück und nimmt nur das Enddrittel der Innenfahne der 2. (ausseren) Feder ein, wogegen sie die gleiche Aussenfahne ganz frei lăsst. Nicht unerwăhnt möchte ich lassen, das Ex. 3 von den Strophaden als atricapilla semitorquata bezeichnet ist, obwohl ich das Weiss an der Halsseite nicht besonders weit nach hinten gehend finde (was doch das Ausschlaggebende ist); wohl aber erinnere ich mich bei einem vor bald 18 Jahren ausgeführten Besuch des Mainzer Museums, ein Exemplar mit exquisiter semitorquataFärbung gesehen zu haben, das aus der Umgebung gestammt haben dürfte und gewiss ein Bastard war, obwohl ein bezüglicher Vermerk fehlte; wegen einer bevorstehenden Transferierung der Sammlung liess sich das interessante Stück, das ich gerne genau untersucht bătte, momentan nicht auftreiben.

(Der Verf.) 
scheint, vielleicht ebenfalls nur jüngere Vögel zur Brut zu schreiten pflegen. Denn während die bayerischen Stücke der Erlegungsdaten ermangeln, stammen die aus Ungarn sämtlich aus der Frühjahrszugzeit, so dass sich nicht sagen lässt, ob es einheimische Exemplare oder nur Durchwanderer waren. Ich traf seiner Zeit in der bayerischen Rhön, wo die Art recht häufig nistet, in der Tat gar keine ganz alten Männchen am Brutplatze an, worüber ich in III. Jahresberichte des Ornith. Verein München p. 230 schon ausführlicher berichtete. Aus der Rheinpfalz meldet mir Freund Bertram die gleiche Erscheinung. Hier in München, wo die Art namentlich im Frühjahr zahlreich durchwandert, bekommt man selbst bei dieser Gelegenheit nur ausnahmsweise einen völlig ausgefärbten Vogel zu Gesicht. Wenn man also nicht vermuten will, dass die alten, rein schwarzweissen Vögel höher nach Norden hinaufgehen - was sich doch schwerlich als richtig erweisen dürfte - so kann man nur annehmen, dass diese Vögel überhaupt relativ selten zu höherem Alter gelangen; jedenfalls haben sie zu der Zeit, da sie bei uns durchkommen, vielfach noch nicht das Hochzeitskleid angelegt, was natürlich im höheren Norden, wo sie später anlangen, immer der Fall sein wird. Es sind auch zweifellos die grosse Mehrzahl der in unseren Sammlungen befindlichen Stücke auf dem Zuge erlegte Vögel. Am wahrscheinlichsten ist, dass die Art mehrere Jahre zu ihrer vollständigen Ausfärbung benötigt. Aber auch im gleichen Frühjahr scheint die Neubildung von frischen Federn sehr langsam von statten $\mathrm{zu}$ gehen und sich jedenfalls oft bis tief in den Mai hinein zu erstrecken. So liegt mir ein anscheinend hochbetagtes Männchen vom 9. Mai aus Hallein vor - wie das übrige Material aus der hiesigen zoologischen Sammlung - , das trotzdem auf Hinterkopf und Hinterrücken noch braune Federn aufweist. Möglicherweise könnten aber diese Reste des Jugendgefieders auch bis zur nächsten Frühjahrsmauser persistent bleiben, womit aber im Widerspruch stehen würde, dass das frische Herbstkleid auch bei den alten stets als dunkelaschgrau angegeben wird. Ich möchte es überhaupt bezweifeln, dass das frisch vermauserte Herbstkleid auch der alten Männchen immer gleich gefärbt erscheint, denn sonst müsste nur bei der Frühjahrsmauser in der Ausfärbung ein Schritt nach vorwärts gemacht werden, was mir doch nicht sehr plausibel vorkommt.

Als Zeichen der Jugend darf im Allgemeinen wohl betrachtet werden (abgesehen von der grösseren Ausdehnung der weissen Farbe in den Steuerfedern der Männchen), wenn die Basen der Sekundären oder selbst die Spitzen der grossen Flügeldecken ausgesprochen ocker- oder rostgelb gefärbt sind; Tafel 20, No. III im "Neuen Naumann" bildet ein solches Exemplar im „mittleren Kleide" ab; diese Färbung ist aber durchaus kein konstantes Merkmal der Jungen, da sie oft nur angedeutet ist; umgekehrt soll nicht unerwähnt bleiben, dass auch bei alten, schon ganz schwarzen 
Vögeln im Frühjahr eine intensive rostgelbe Kolorierung der Armschwingenbasen vorkommen kann.

Einen stark gelbbräunlich angeflogenen Kropf und so gefärbte Brustseiten fand ich nur bei 2 Exemplaren; es sind entschieden junge Vögel im Herbstkleid; der eine ist als Weibchen bezeichnet; nach Naumann wären junge Männchen und Herbstweibchen identisch gefärbt.

Über das Vorkommen des Trauerfliegenschnäppers in Griechenland lauten die Angaben der Autoren verschieden. Lindermayer hat ihn gar nicht beobachtet, Kr üper bezeichnet ihn als selten auf dem Durchzuge und erhielt nur ein Stück, Drummond zahlreich auf Korfu während des Zuges; als Passatvogel auf den Cycladen erwähnt ihn Erhardt; v. der Mühle erhielt ihn häufig im Herbst, wie er erwähnt, nie im Hochzeitskleid, was nach dem oben Gesagten nicht verwunderlich erscheint. Die $\mathrm{Naumann}$ 'sche Angabe, die Art sei sehr gemein in Griechenland, ist also in dieser allgemeinen Fassung nicht richtig. Als Brutvogel kommt sie nach neueren Autoren verhältnismässig selten vor; ein sicherer Brutnachweis dürfte aber überhaupt noch nicht erbracht sein. Die Hauptzugsstrasse scheint mehr im westlichen Teile Griechenlands gelegen und jedenfalls hauptsächlich über die vorgelagerten Inseln hinwegzugehen.

Zum Schlusse lasse ich die Masse der mir aus Mitteleuropa vorliegenden Stücke folgen:

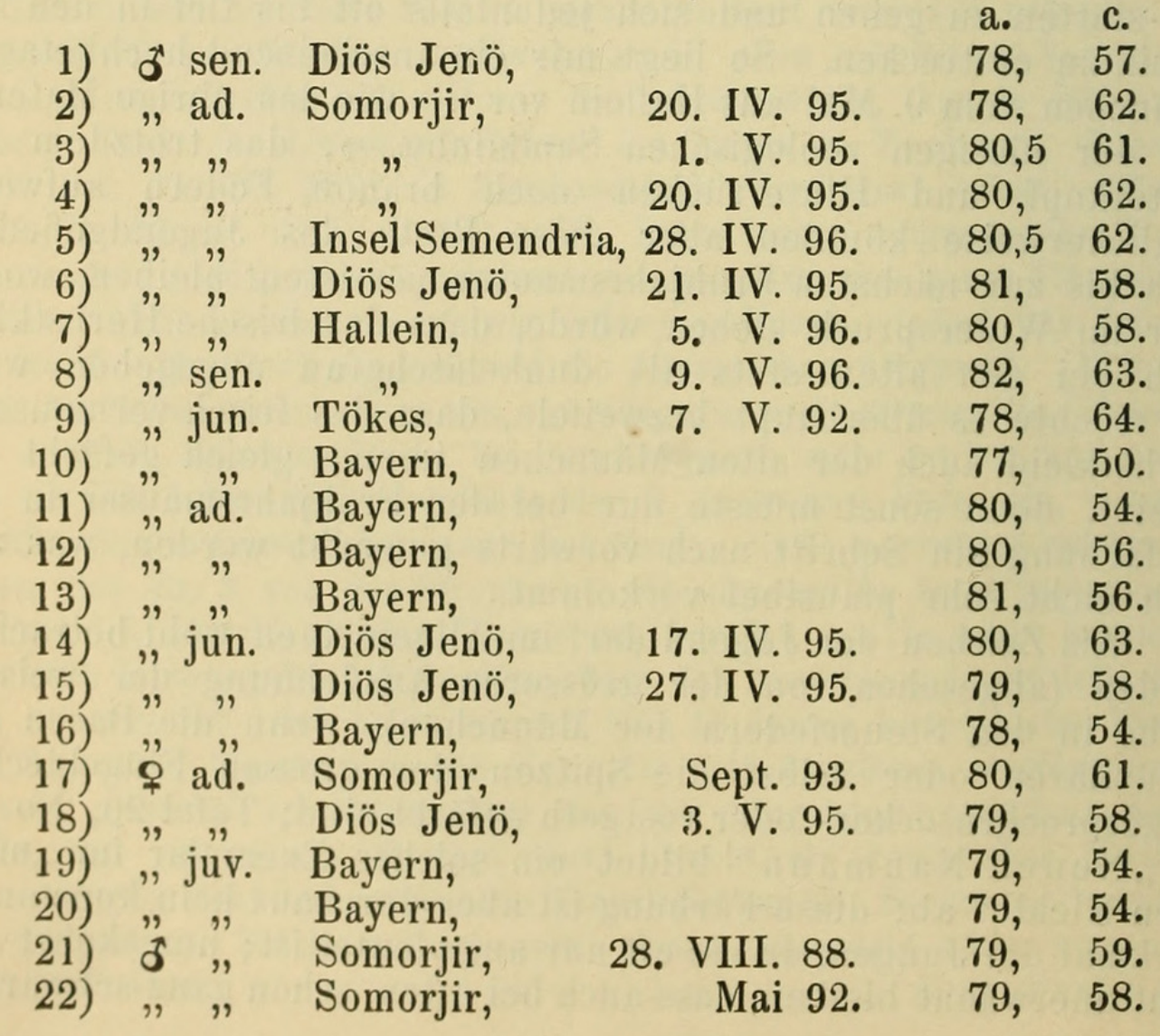




\section{Muscicapa collaris Bchst.}

Viel allgemeiner als die vorige Art wird der Halsbandfliegenschnäpper auf dem Durchzuge (vielleicht auch als Brutvogel) in Griechenland gefunden. Seine Zugzeit fällt etwas früher; von der Mühle erhielt ihn nur im Frühjahr, anfangs April schon, jedoch nur wenige Tage hindurch, und alle im ausgefärbten Kleide. Dass der Durchzug bis in den Mai hinein währt, beweisen mir 2 am 7. resp. 9. Mai auf den Strophaden gesammelte ältere Männchen, die insofern merkwürdig sind, als sie beide einen sehr kleinen und ganz wenig hervorragenden Handschwingenspiegel aufweisen; nach den Massen und nach der Schmalheit des erst in der Entwicklung begriffenen Stirnflecks zu urteilen, ist das zuletzt erbeutete Männchen, das den kleinen Spiegel wenigstens teilweise unverdeckt trägt, etwas jünger, sonst stimmen beide in der vollständigen Ausfärbung der Oberseite ganz miteinander überein. Richtig scheint zu sein, was Naumann hervorhebt, dass die jüngeren und weiblichen Vögel mehr weiss in den Schwanzfedern zeigen. Bei den vorliegenden Exemplaren sind letztere aber ganz schwarz und trägt nur die äusserste einen sehr schmalen weissen Rand. Die Oberseite scheint bei den collaris-Weibchen weniger bräunlich gefärbt, wie beim weiblichen Vogel von atricapilla. Die mir zum Vergleich vorliegenden alten Frühjahrsweibchen von collaris zeigen einen fast gerade so grossen Handspiegel wie die ältesten Männchen. Desto auffälliger muss der verkümmerte Spiegel bei den Strophadenvögeln erscheinen. Vielleicht haben wir auch hier Vögel vor uns, die eigentlich der Gruppe semitorquata angehören, wenn auch das Hauptcharakteristicum fehlt. Die Entwicklung des Handspiegels schreitet wohl mit zunehmendem Alter fort; nicht immer hält damit die Aushildung des Stirnflecks Schritt, der manchmal schon sehr frühzeitig vollständig ausgebildet erscheint. Ganz alte Männchen erkennt man wohl am Besten an der grösseren Ausdehnung des Weiss auf den innern Sekundären, welches dann den grössten Teil der Innenfahne einnimmt. Diese Zeichnung wird übrigens von ganz alten atricapilla-Männchen fast erreicht. Gleichzeitig damit bemerkt man eine Zunahme der weissen Farbe auf den Flügeldecken. Ein ockergelblicher Anflug an dieser Stelle, wie er sich bei atricapilla (wohl auch in der Ohrgegend) bisweilen findet, liess sich bei vorstehender Art nur bei Exemplaren im Nestgefieder konstatieren. Zwei derartige in der hiesigen Staatssammlung stehende Stücke vom Juni 1834 aus München (wo also damals die Art schon Brutvogel war) haben die grossen Flügeldecken breit gelblich endigend; dann zeigt auch jede schwarzbräunliche Rückenfeder ein gelbliches Centrum, ähnlich wie bei dem „pullus" von Muscicapa parva; die Unterseite erscheint „geschuppt“, indem die weisslichen Federn gegen die Spitze $\mathrm{zu}$ trüb dunkelbraun gerandet sind. 
In der mir vorliegenden Serie von Halsbandfliegenschnäppern deren Masse jetzt aufgeführt werden sollen, findet sich auch ein hahnenfedriges Weibchen (No. 30), das die vollständige Ausfärbung eines alten Männchen erreicht hat und eine stattliche Grösse zeigt. Das Exemplar entstammt, wie alle Ungarn, der v. Almásy'schen Sammlung, welche in den Besitz des hiesigen Museums übergegangen ist. Die Vögel von Gîze (Kairo) habe ich selbst gesammelt.

1) đa ad. Strophaden,

2) ",

3) " " Gîze"

4) " " Diös Jenö

5) " " " "

6) " " " " "

7) " " " ,

8) " $, ", \quad, 1$ )

9) $", "$,

10) " " " "

11) " " "

12) " " "

13) "(2jähr.)" ,"2)

14) "ad. Leka

15) " " Diös Jenö

16) "sen.

17) "ad "

18) " " " " "

19) " , " ,

20) " " " "

21) " "

22) " "

23) " "

24) " jü. Diös Jenö

26) "(2jähr?), " $\left.{ }^{3}\right)$

27) "juv. Bayern

28) ? " Gîze

29) \& ad. Somorjir

30) "sen. Ungarn

31) " " Diös Jenö

32) ", , ,

33) " " " "
9. V. 04 .

7. V. 04 .

25. IV. 02.

6. V. 95 .

18. V. 95.

6. V. 95 .

6. V. 95.

3. V. 95 .

20. V. 95.

10. V. 95.

13. V. 95 .

20. IV. 94.

14. IV. 96. 1893.

24. V. 95.

18. V. 95 .

22. V. 95.

23. V. 95 .

29. V. 95 .

20. IV. 98. a. c.

$79, \quad 54$.

$82, \quad 57$.

81,55 .

$84,56$.

$84,58$.

$82,57$.

83,558 .

$79, \quad 52$.

$79, \quad 57$.

83,561 .

84,61 .

$82,56$.

$82, \quad 57$.

84,56 .

82,61 .

83,561 .

$83,56$.

$84,56$.

$81,56$.

$82,56$.

$82, \quad 57$.

$83, \quad 57$.

$80, \quad 59$.

$80,56$.

$81,57$.

$82, \quad 58$.

76,55 .

$84, \quad 56$.

$83, \quad 56$.

$84,59$.

$81,57$.

$82, \quad 56$.

$81,56$.

1) Mit kaum sichtbarem Handspiegel, aber grossem Stirnfleck. Primăren alt, nicht vermausert.

$\left.{ }^{2}\right)$ Handspiegel måssig gross.

3) Im Übergangskleid; Hinterrücken schon ganz schwarz, Handspiegel sehr gross, Kopf brăunlichgrau, an den Seiten des Hinterkopfes etwas schwarz; Stirnfleck beginnend (grau und weiss melirt). 


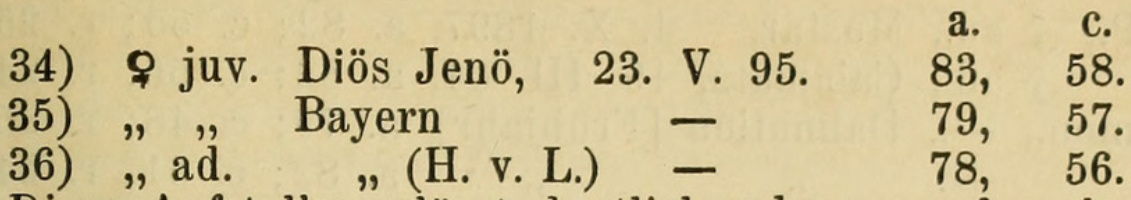

Diese Aufstellung lässt deutlich erkennen, dass bei Muscicapa collaris die Flügellänge wohl meist eine etwas beträchtlichere ist als bei atricapilla, dass aber der Schwanz im Verhältnis geringere Dimensionen aufzuweisen pflegt. Es ist diese Verschiedenheit so auffallend (die eigentümlich geringen Schwanzmasse bei ausgestopften atricapilla-Exemplaren aus Bayern finden vielleicht in der Präparationstechnik ihre Erklärung, sollten jedenfalls nicht als "massgebend" angesehen werden), dass dieselbe geradezu als differenzialdiagnostisches Merkmal aufgestellt werden darf.

Den Schnabel von $M$. collaris finde ich in der Regel breiter, wohl auch etwas länger wie bei ihrer Verwandten.

\section{Sitta europaea caesia Wolf.}

Am 23. März vernahm ich unweit der Passhöhe bei Grammeni Petra den Ruf des Kleibers.

\section{Sitta neumayeri Michah.}

Ich traf diesen munteren Vogel, der mir von der Herzegovina her in angenehmster Erinnerung geblieben, zuerst am 19. März bei Calamata oberhalb Kloster Hag-Elias auf dem zerklüfteten und tuffsteinartig gehöhlten Gestein der unzugänglichsten Partien einer Schlucht mehrfach an; es bedurfte aber längeren Nachsteigens, bis ich endlich des Vogels, dessen Lockton ein leiser, meisenartiger ,zi“" Ton, und dessen Gesang, das bekannte helle, zugleich schmetternd, flötend und trillernd klingende ,djoi djoi djoi djo", aus verschiedenen Richtungen zu mir herabschallte, ansichtig wurde. $\mathrm{Zu}$ sehen bekommt man die ungemein lebhaften Tiere eigentlich nur, wenn sie auf der Spitze eines Steinblocks erscheinen, und, dabei den Gesang gewöhnlich nur bruchstückweise vortragend, nach dem Störenfried Ausschau halten. Zweimal sah ich Exemplare unter Steinplatten verschwinden, es wollte mir aber nicht gelingen, ein Nest zu finden; dass dies immerhin im Bereich der Möglichkeit gelegen gewesen wäre, bewies mir ein Felsenkleiber, der am 25. März oberhalb Whelanidiá mit einem Räupchen im Schnabel an einer Felswand emporkletterte, und sich dann an einem kleinen Loche zu schaffen machte. Es war mir interessant, einen Vogel auch an die Steinwälle herabkommen zu sehen, welche die obersten mit kleinen Feigenpflanzungen bestandenen Plateaus umgeben.

Am 3. April vernahm ich den Gesang in der Klissuraschlucht (Akarnanien).

Es folgen die Mafse einiger Vögel:

Journ. f. Orn. LUI. Jahrg. Juli 1905. 
1. Coll. P., ơ ad., Mostar, 4. X. 1897 , a. 82 ; c. 55 ; r. 25 ;

2. \" ad, Calamata, 19. III. 04 , a. 82 ; c. 56 ; r. 24 ;

3. Mus. mon., - Dalmatien [Frühjahr], a. 79 ; c. 48 ; r. 25 ;

4. $" \quad$ - $", \quad$ a. $82 ;$ c. $51 ;$ r. 24 ;

5. $"$-. " " a. $81 ;$ c. $50 ;$ r. 24 ;

6. $" \quad-$ Griechenland, ",$\quad$ a. $79 ;$ c. $51 ;$ r. 24,3 ;

7. $" \quad-$ Südeuropa, $"$ a. $81 ;$ c. $48 ;$ r. 24,5 ;

8. $"$ - ? " a. $75 ;$ c. 47 ; r. 24,75 ,

Es hat den Anschein, als ob die griechischen Vögel schon etwas zur S. neumayeri syriaca Temm. hinüberleiteten. Die Steuerfedern haben übrigens auch bei den Dalmatinern durchaus nicht immer sämtlich einen rostfarbigen Endfleck, bei dem Herzegoviner (Herbst!) zeigt ihn sogar nur eine Feder deutlich, bei No. 2 sind nur die Innenfahnen einzelner Federspitzen so gefärbt. Ich glaube, man darf auf dieses schwankende Merkmal nicht allzuviel Gewicht legen, ebensowenig auf das Vorhandensein oder Fehlen eines rostfarbigen Aussensaums an den grösseren Flügeldecken und Armschwingen; ein solcher ist z. B. bei No. 6 vorhanden. Bei Prüfung dieser Verhältnisse sollte allerdings nur das frische Herbstgefieder als massgebend betrachtet werden, da die abgeriebenen und gebleichten Federn gerne ein fuchsiges Kolorit annehmen, während die rostfarbigen Töne an den Steuerfedern im Frühjahr durch Abstossung zu schwinden scheinen. Bei allen vorliegenden Stücken ist der Augenstreif durchaus nicht schmal, er geht bis zur Seite des Nackens nach hinten, ein Nackenband, das übrigens auch bei der anscheinend grösseren syriaca oft nur angedeutet ist oder sogar fehlt, ist nicht $\mathrm{zu}$ bemerken.

Das von Hellmayr im ,Tierreich" (Lief. 18. p. 174) gegebene Maximaflügelmass bei der europäischen Form ist 82 , Kollib a y fand 83 .

Was Kollibay am Schluss seiner Ausführungen über $S$. neumayeri (J. f. 0. 1904 S. 467) bez. der direkt komisch wirkenden Hinweglassung des „," $"$ am Ende des Wortes sagt, vermag ich vollständig zu unterschreiben; er spricht mir aus der Seele, wenn er das Verfahren als eine „unzulässige und zu unzuträglichen Konsequenzen führende Überspannung des Prioritätsprinzips" ansieht. Ich glaube ebenfalls im Interesse unserer Wissenschaft vor allen irgendwie vermeidbaren Änderungen und Umstellungen al teing e bü rg erter $\mathrm{N}$ am en (Turdus musicus, Pyrrho$\operatorname{corax}$ etc.) ausdrücklichst warn e n zu sollen. -

\section{Certhia brachydactyla Brehm.}

Am 23. März glückte es mir, im Kiefernwald unterhalb Grammeni-Petra (in der Richtung gegen die Langada) in etwa $1250 \mathrm{~m}$ Seehöhe ein „zi zi zi“ lockendes Exemplar zu erlegen. In der Färbung der Oberseite gibt sich der Vogel als typische brachydactyla zu erkennen, so auffällig es auch erscheinen mag, 
dass er hier im Gebirge und im reinen Kiefernwald haust. Leider hörte ich ihn nicht singen, sonst hätte die Balgbestimmung sicherlich in der charakteristischen Strophe eine Bestätigung gefunden. Da ich später an anderem Orte ausführlicher auf meine Erfahrungen in der interessanten Baumläuferfrage zurück zu kommen gedenke, gebe ich hier nur die wichtigsten Masse: a. $58 ;$ r. 16,$3 ; \mathrm{Kr} .7$. Über die Bedeutung der bei beiden Arten stark differierenden Schnabellänge bin ich mir noch nicht klar geworden; es gibt auch exquisit kurzzehige Baumläufer mit sehr schwachem Schnabel, das ist der Fall z. B. bei einem aus Serbien stammenden, dem vorstehenden Stücke sehr ähnlich gefärbten Exemplare.

\section{Parus maior peloponnesius nov. subsp.}

Die Kohlmeise ist um Calamata in Gärten und Olivenhainen häufig vertreten. Der Lockton der dortigen Vögel klingt nicht anders wie bei uns, er scheint nur um eine Silbe länger. Im freien Gelände zeigen sie sich scheuer, wie in geschlossenen Gärten. Am 21. März war ich hinter einem gepaarten Paar, das in einem Olivenhain seinen Standort hatte, her; endlich erlegte ich das W eibchen, darauf zeigte sich der Gatte äusserst erregt, lockte sehr melodisch und liess auch einige flötende, zärtlich klingende Töne hören, dabei aller Vorsicht vergessend, sodass es mir ein leichtes war, auch seiner habhaft zu werden. Um Ladá war die Kohlmeise ebenfalls häufig zu sehen; zweimal begegneten mir Gesellschaften von 4-5 Stück, die doch kaum aus heurigen Jungen bestehen konnten. Sonst notierte ich mir die Art noch an den Seen von Angelocastro und auf Corfu. Die Masse von 7 bei Calamata, teilweise von mir selbst, erlegten Stücken sind folgende: No. 979 . o ad. 21. III. 04 ; a. 73 ; c. 63,$5 ;$ r. 12,5 (gepaartes

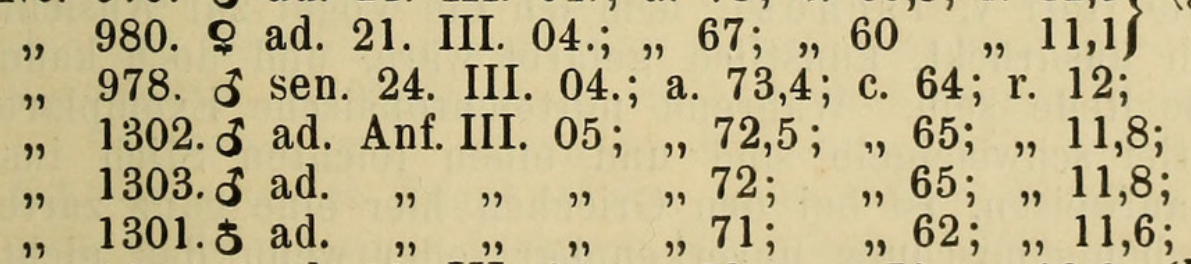

981. o ad. 23" III. 04 ; a." 73,4 ; c. $70 ;$ r. "12,8; (Langada)

Es ergibt sich hieraus, dass die Exemplare aus der messenischen Ebene ${ }^{1}$ ) in ihren Körperdimensionen entschieden hinter mitteleuropäischen Exemplaren zurückstehen. Ich finde bei diesen, auch bei Exemplaren aus Ungarn, und selbst solchen aus Konstantinopel, wo die typische Kohlmeise mindestens Wintergast zu sein scheint, konstant eine Flügellänge von $74-77 \mathrm{~mm}$ bei

1) Das zuletzt aufgeführte Stück, ein Gebirgsvogel aus Lakonien, zeigt auffallender Weise nicht die bei andern gefundenen Merkmale, sondern gleicht viel eher der gewöhnlichen Kohlmeise, sowohl in der Farbe, als auch teilweise in den Massen, denn sein Schwanz ist im Verhăltnis merkwürdig lang.

(Der Verf.) 
Männchen, von $71,5-73$ bei Weibchen. Noch stärker erweist sich ein in der hiesigen Staatssammlung vorhandenes Männchen vom Altaigebirge, das bei einer Gesamtlänge von $155 \mathrm{~mm}$ am Flügel $78 \mathrm{~mm}$ misst, sonst aber, wenn man von dem sehr kräftigen Medianstreif der Unterseite und dem besonders deutlichen weissen Nacken band absieht, dadurch ausgezeichnet ist, dass die erste Steuerfeder nur auf der Innenfahne einen grösseren, weissen Fleck trägt, eine Differenz, die bei der sonst vorhandenen Konstanz der Farbenanordnung immerhin auffallend erscheint, aber bei dem Fehlen weiteren Materials aus dem Osten nicht weiter nachgeprüft werden kann. Es ist nun bemerkenswert, um gleich bei der Schwanzzeichnung zu bleiben, dass auch bei den Griechen das Weiss auf der Innenfahne der ersten Schwanzfeder eine schmalere Anordnung zeigt. Dass auch sonst eine Tendenz zum Überwuchern der schwarzen Farbe über die helleren Partien des Körpers vorhanden ist, scheint aus der Färbung des Ex. No. 978 ersichtlich, bei welchem das Schwarz in einer Weise vermehrt ist, wie es wohl hier zu Lande auch bei ganz alten Männchen nur ganz ausnahmsweise vorkommen mag. Bei den griechischen Vögeln gehen die ausgedehnt schwarzen Halsseiten in breitester Kontinuität in das Schwarz der Kehle über; von hier aus setzt sich, ebenfalls breiter wie sonst, der Medianstreif auf Kropf und Brust fort, um sich dann auf dem Bauche zu einem sehr ansehnlichen, in dem genannten Falle $20 \mathrm{~mm}$ breiten, Flecke auszudehnen. Aber noch eine andere Verschiedenheit, auf die entschieden grösseres Gewicht zu legen ist, springt in die Augen und zwar am deutlichsten gerade bei dem mit schmalem Medianstreif ausgestatteten Weibchen: Sämtliche Stücke aus der Ebene tragen auf der Unterseite ein ganz anderes Gelb; dasselbe sieht manchmal aus, als wenn es, wie Herr v. Tschusi, dem ich die Vögel zur Ansicht sandte, sich ausdrückt, künstlich gefärbt wäre, und doch kann davon keine Rede sein. Während mitteleuropäische Exemplare unterseits tief schwefelgelb sind und einen leichten Stich ins Grünliche aufweisen, ist bei den Griechen hier eine ganz zarte rötliche Farbenbeimischung unverkennbar, oder wenn das nicht der Fall sein sollte, so ist doch ein reineres Gelb vorhanden, welches, obwohl heller, doch eine höhere Entwicklung (in der Richtung gegen das Orangegelb hin) erkennen lässt. Diese letztere Färbung, welche entschieden dem Kolorit süddalmatinischer Vögel, für die Kollibay (l. c. p. 459) den Namen sulfureus vorgeschlagen hat, nahe stehen dürfte, trägt auffallenderweise nur das eine Exemplar No. 979. Wir haben hier also einen förmlichen Dimorphismus der Unterseitenfärbung bei Exemplaren der gleichen Jahreszeit vor uns, der schwer zu erklären ist, wenn wir nicht annehmen wollen, dass die Differenz durch verschiedene Altersstufen bedingt ist. Dem steht allerdings im Wege, dass gerade das Exemplar, welches durch starke Entwicklung des Schwarzen sich als ganz alter Vogel kennzeichnet, eine blassere, mehr nach 
dem Strohgelb hinneigende Nuance zeigt. Am lichtesten und fahlsten aber präsentiert sich Exemplar 1303, bei dem auch ein ganz zarter, rosafarbiger Anflug über einem bleichen Strohgelb ausgebreitet liegt. Interessant ist aber, dass einige seitliche Kropffedern doch rein kanariengelbe Enden aufweisen, woraus hervor zu gehen scheint, dass bei diesen Vögeln das Unterseitengefieder im Frühjahr einer, wenigstens partiellen, Erneuerung unterworfen ist; wenn daneben die bleich gefärbten Federn des Unterkörpers durchaus nicht die Spuren einer Abnutzung und künstlichen Bleichung darbieten, so kann ich mir diese Erscheinung nur dadurch erklären, dass sie ebenfalls frisch gewachsen und im Begriffe waren, mit dem intensiver gelben Pigment sich anzufüllen; das Letztere konnte ich allerdings nicht nachweisen. Es läge dann auch die Annahme nahe, dass dieses Exemplar ein jüngerer Vogel war, der gerade ein stationäres Übergangskleid trug, dass also ähnliche Verhältnisse vorlägen, wie bei den Trauerfliegenschnäppern. Das eben besprochene Exemplar steht, was nicht übersehen werden kann, jedenfalls dem cyprischen Parus maior aphrodite (Mad.) ausserordentlich nahe, kann aber als einem Jugendstadium angehörig, nicht damit identifiziert werden. Die beiden Männchen No. 978 und 1302, welche etwas ältere Vögel darstellen dürften, beweisen im Gegenteil, durch die kräftigere, wenn auch immer noch etwas unreine und ins rötliche spielende Färbung der Unterseite, dass das normale Kolorit der südgriechischen Kohlmeisen nach der ausgesprochen gelben Seite hinneigt. Auch lässt die Färbung der beiden vorliegenden Weibchen, bei welchen dem Gelb ein deutlich ockerroter Ton beigemischt ist, die für den alten Vogel charakteristische Färbung erkennen. $\mathrm{Ob}$ das Exemplar No. 979 die typische Färbung repräsentiert oder vielleicht nur eine Art Rückschlag nach dem Kolorit der nördlicher wohnenden Verwandten darstellt, muss vorläufig dahingestellt bleiben.

Es wäre wohl daran zu denken, ob die bei der Mehrzahl der vorliegenden Vögel stärker abweichende Färbung der Unterseite vielleicht einer äusseren Einwirkung, etwa dem Staube der roten Erde, mit welcher die Vögel in den Olivgärten in Berührung kommen, zuzuschreiben sein würde; doch macht das Kolorit durchaus nicht den Eindruck, als ob irgend eine Verunreinigung bestünde, da gerade die beiden Extreme völlig reine Farben aufweisen. $\mathrm{Zu}$ bemerken wäre noch, dass die beschriebene Differenz mehr noch, als das jetzt am toten Balg der Fall ist, bei den frisch erlegten Vögeln in die Erscheinung trat, sodass ich sofort beim Aufheben vom Boden im Klaren war, hier etwas abweichend Gefärbtes in Händen zu haben.

Erwähnenswert erscheint schliesslich, dass die Endflecke an den grossen Flügeldeckfedern bei den Griechen schmaler und statt weisslich mehr rahmfarbig sind, ferner dass das Saftgrün der Oberseite, welches weniger weit nach unten reicht, meist etwas verdüstert ist. Von den Unterschwanzdecken ist hier das 
mittlere Paar schwarz, die folgenden haben einen breiten weissen Aussenrand, die äussersten sind ganz weiss, eine Farbenzusammenstellung, die übrigens auch bei unsern Kohlmeisen häufig vorkommt.

Nach alledem wird man es verstehen können, dass ich, so vorsichtig ich auch mit der Kreierung neuer Formen verfahren wissen möchte, die in der messenischen Ebene heimischen Kohlmeisen für genügend gekennzeichnet ansehen muss, um ihre $\mathrm{Ab}$ trennung von der Stammform gerechtfertigt erscheinen zu lassen; es mag andererseits zugegeben werden, dass die neue Form in ihrer sichtlichen Neigung, nach der einen oder anderen Seite hin auszuschlagen, als etwas völlig Konstantes noch nicht betrachtet werden kann und dass sie mindestens erst in den litoralen Teilen des Landes zur Ausbildung gelangt ist, während die Gebirgsvögel noch mehr der Stammform zu gleichen scheinen.

\section{Parus palustris (L.)} bei Ladá.

Am 22. März sah ich ein Exemplar in Olivenpflanzungen Parus ater (L.)

In den Kieferwäldern der Vorberge des Taygetos (besonders bei ca. $1300 \mathrm{~m}$ ) war diese Meise wohl der häufigste Vogel, der zur Beobachtung gelangte; der bekannte Lockton war in einem fort $\mathrm{zu}$ hören, doch wollte es durchaus nicht gelingen, eines der flinken und hier auffallend scheuen Tierchen habhaft zu werden.

\section{Parus coeruleus (L.)}

In Corfu sah ich an der Promenade ein Exemplar.

\section{Parus lugubris graecus Reiser.}

Am 19. März erlegte ich beim Kloster Hag Elias unweit von Calamata ein Männchen dieser Unterart. Dasselbe ist insofern nicht ohne Interesse, als es eine Art Übergang zu der nördlicher wohnenden Stammform" ${ }^{1}$ bildet, da von einer ,"lichtbraunen" Kopfplatte hier durchaus keine Rede sein kann; die Federenden der

1) Ein mir vorliegender Frühjahrvogel von Mostar (Geschlecht nicht bestimmt!) zeigt die Kopf- und Kehlfarben relativ wenig "verblichen.“ Die schwarzbraunen Kopffedern lassen am Ende eine gelblichbraune Beimischung erkennen, wodurch der Eindruck des Fablen hervor gerufen wird, ganz wie bei dem obigen Vogel. Der Rücken erscheint gelbbraunlichgrau, auf dem Bürzel mehr hellbrăunlich, mit einem leichten Stich in's Gelbliche. Die trübweisse Unterseite zeigt nur einen ganz geringen brăunlichen Anflug an den Seiten und in der Bauchgegend. Rostfarbige Tơne fehlen auch hier ganz. Ich messe bei diesen Vogel, der einen etwas stärkeren Eindruck macht: a. 73; c. 72; r. 12. (Der Verfasser.) 
letzteren erscheinen allerdings bei genauem Zuschauen und bei günstigster Beleuchtung fahlgelbbräunlich, diese Farbe ist aber so verdüstert, dass aus geringer Entfernung schon der Eindruck des Mattschwarzen resultiert. Ebenso sehen Kinn und Kehle braunschwärzlich aus, allerdings so fahl und mit einem scheinbar so stark verblichenem Aussehen, dass eine weitere Aufhellung in "Lichtbraun" bei vorgeschrittenerer Jahreszeit wohl möglich wäre. Da, wie ich sehe, auch die Typen des echten graecus im Museum Sarajevo voin Ende April stammen, so ist der Gedanke nahe liegend, dass hier eine wirkliche Verbleichung vorliegt, und dass die Herbstfärbung der genannten Teile eine andere ist. Kropf und Brust sind bei meinem Exemplar braun überwaschen, während der Bauch rein bräunlichweiss genannt werden muss. Den Rücken finde ich fahlgraubraun, die Bürzelgegend etwas heller gefärbt; von rostfarbenen Tönen im Gefieder ist nichts zu sehen. Der vorliegende Vogel weist eine relativ beträchtliche Flügellänge auf und nähert sich also auch insofern etwas der nördlicheren Form. Der Erlegungsort befindet sich ca. $200 \mathrm{~m}$ ü. M.

Wie Reiser ausführt, scheint die griechische Trauermeise hauptsächlich auf das litorale Gebiet beschränkt zu sein. Hier noch die Masse meines Vogels: a. 73 ; c. 64 ; r. 12,5 .

\section{Coracias garrula (L.)}

In Calamata wurde mir ein ausgestopftes Exemplar zum Kaufe angeboten; die Art ist also dort mindestens Durchzügler. Auf den Strophaden kam sie Anfangs Mai 1904 zur Erlegung.

\section{Iynx torquilla (L.)}

Ich gelangte in den Besitz eines schon am 20. März bei Calamata erbeuteten Weibchens; das unterseits besonders lebhaft gefärbte Stück zeigt nicht nur Kehle und Kropf stärker gelb wie sonst, sondern es finden sich auch auf der Vorderbrust noch zerstreute rostgelbbraune Fleckchen, die wie (künstliche) „Rostflecken" aussehen, es aber doch nicht sind. Auch die etwas tiefer herabreichenden braunschwärzlichen Bogenlinien der vorderen Unterseite sind kräftiger entwickelt als z. B. bei einem aus der gleichen Jahreszeit stammenden, überhaupt blasser gefärbten Weibchen aus Konstantinopel; die feinste Zeichnung und das blasseste Kolorit weist aber ein gleichfalls weiblicher FrühjahrsVogel von meinem hiesigen Jagdrevier, wo die Art allerdings nur durchwandert, auf. Die Masse der drei Exemplare, verglichen mit denen einer Anzahl anderer im Münchener Museum vorhandener Stücke, sind folgende:
1) \&, Calamata,
2) "Konstantinopel,
a. c. r.
20. III. $04.87,74,16,5$.
25. IV. $04.88,71,16$. 


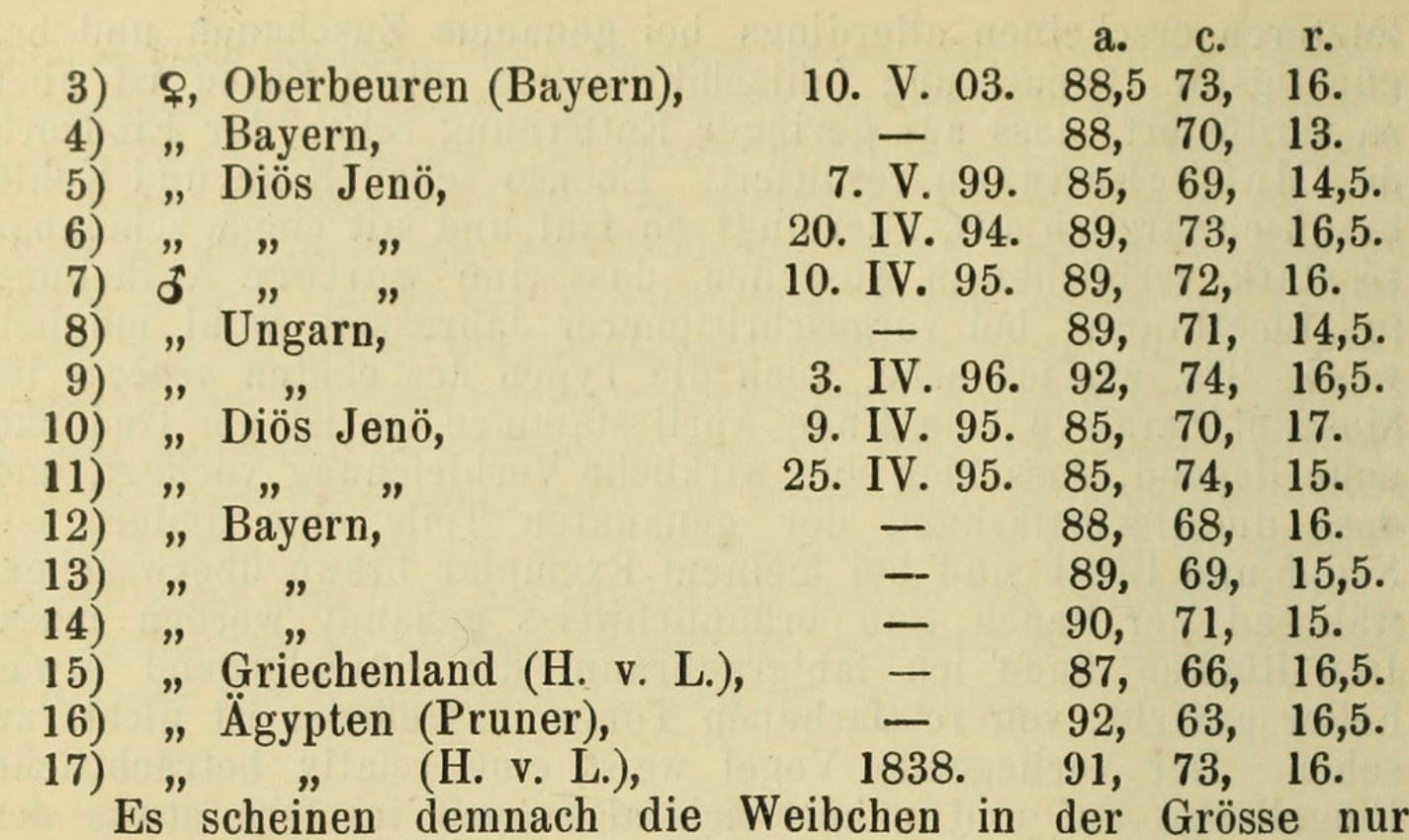
wenig hinter den Männchen zurück zu stehen. Das im „Neuen Naumann" angegebene Schwanzmass ist natürlich viel $\mathrm{zu}$ gering, das Flügelmass (175!) direkt unmöglich. Was die Färbung anlangt, so lässt sich zwischen Männchen und Weibchen ein durchgreifender Unterschied nicht konstatieren. Sehr wechselnd ist die Intensität des Gelben auf der Unterseite, dass ich allerdings bei einem Männchen (No. 7) am stärksten entwickelt finde. Die Fleckung erscheint auffallend spärlich bei No. 5 (Weibchen). Rostflecken sind bei allen Exemplaren vorhanden; am deutlichsten zeigen sie sich aber bei meinem Weibchen aus Griechenland. Meist relativ schmal, präsentiert sich die Kehl- und Kropfbänderung, ausnehmend fein bei Ex. 3 ; noch am stärksten ist sie bei No. 10. Die beiden Stücke aus Ägypten sind im Ganzen identisch mit mitteleuropäischen gefärbt; es besteht nur bei dem ersten Vogel von dort ein auffallendes Missverhältnis zwischen Total-, Flügel- und Schwanzlänge, indem das ausnehmend schwache Exemplar einen verhältnismässig sehr langen Flügel aufweist; dabei erscheint die Oberseite bei ihm auffallend verdüstert, die Unterseite ziemlich intensiv gelb. Da auch No. 15 aus Griechenland mit dem letzterwähnten Stück grosse Ähnlichkeit zeigt, so dürfte es sich vielleicht bei grösseren Vergleichsmaterial später ermöglichen lassen, solche etwas abweichend gefärbte Exemplare auch auf ihre event. verschiedene Brutheimat hin anzusprechen. Es macht nämlich den Eindruck, als ob im Nordwesten des Verbreitungsgebietes der Art die grauen Partieen des Gefieders an Reinheit zunehmen, die gelben Töne aber abnehmen würden, während die im Osten, vielleicht auch die im Süden beheimateten Vertreter die Oberseite mehr verdüstert, die Unterseite aber intensiver $u$. ausgedehnter rostgelb gefärbt und dabei breiter gewellt zeigen. Es scheint mir sehr wahrscheinlich zu sein, dass wir in den Griechenland auf dem 
Zuge besuchenden Wendehälsen z. T. Fremdlinge aus dem fernen Osten $\mathrm{zu}$ erblicken haben. In wie weit diesen ja geringen, aber doch unleugbar vorhandenen Färbungs- und Grössendifferenzen eine bestimmte Regelmässigkeit innewohnt, das lässt sich natürlich an der Hand dieses geringfügigen Materials nicht entscheiden; Ich erkenne nur, dass zwei aus Sikkim (Himalaya) vorliegende Stücke der hiesigen Staatssammlung eine Art Zwischenstufe zwischen den Europäern und der zweifellos subspecifisch abtrennbaren japanischen Form, die schon von Bonaparte unterschieden, neuerdings aber von Seebohm¹) verworfen wurde, darstellen.

Der Wendehals ist nach $\mathrm{Krüper}$ ein seltener Vogel in Griechenland; es sollen übrigens dort schon einige Exemplare überwintern.

\section{Cuculus canorus (L.)}

Man sammelte diese Art ebenfalls Ausgangs April oder Anfangs Mai auf den Strophaden.

\section{Dendrocopus medius (L.)}

Zwei von Hag Saranti (Epirus) erhaltene Männchen des Mittelspechts gaben mir Anlass, auch dieser Art mein Interesse

1) Seebohm sagt (The Birds of the Japanese Empire, London 1890) es werde behauptet, das japanische Stücke kleiner und blasser seien, als die typische europäische und asiatische Form, welche Feststellung aber ganz unbegründet sei. Diese Charakteristik ist allerdings unrichtig, denn die Iynx torquilla japonica Bp. zeichnet sich im Gegenteil durch wärmere (rötere) und dunklere Kolorierung aus; der Rücken ist breiter schwarz geschaftet, die Flecken am Hinterkopf sind kräftiger entwickelt; ausserdem ist das Grau durch die breiter rostbraunen Federenden, welche besonders auf der Stirn sichtbar sind, verdunkelt. Die Unterseite dagegen ist auffallend stark rostgelb, welche Farbe nicht nur Kehle und Kropf intensiver bedeckt, wie bei den hiesigen Exemplaren, sondern sich auch, nur wenig blasser, bis auf die Unterschwanzdecken fortsetzt. Die Wellenlinien sind dabei viel kräftiger und breiter als gewöhnlich. Schliesslich zeigen die Japaner bedeutend kleinere Dimensionen, wie aus den Massen von 5, von Professor Haberer aus Mitteljapan mitgebrachten, Exemplaren hervorgeht; diese messen nur a. $74-79$, c. $69-71$, r. $15,5-$ 17,75. Es ist auffallend, dass nur der eine Vogel aus Sikkim die grősste Âhnlichkeit mit den Japanern zeigt, während der andere etwas stårkere in der Färbung mehr nach den Europäern hinneigt, ohne aber ganz damit identisch zu sein; beiden scheint allerdings der breite schwarze Hinterkopffleck und ebenso die ansehnlichere Rückenschaftung zu fehlen, und auch die rostbraune Farbe tritt auf der Oberseite weniger in die Erscheinung; die Unterseite zeigt aber wieder, besonders bei dem kleineren Stück, ganz das gleiche Kolorit und die gleiche Zeichnung wie der japanische Vogel.

(Der $\nabla \in r f$. 
zuzuwenden und einige vergleichende Untersuchungen anzustellen. Was das Kolorit der griechischen Vögel anlangt, so leitet es unverkennbar nach dem in jeder Hinsicht noch intensiver gefärbter kleinasiatischen Vertreter der Art, Dendrocopus medius santijohannis Blanf., hinüber; sie stehen also so zu sagen in der Mitte und es fragt sich, ob sich genügend Merkmale auffinden lassen, auch diese Form nomenklatorisch zu kennzeichnen. Die lebhaft karminrote Kappe scheint etwas weiter nach rückwärts zu gehen, wie bei unsern Exemplaren; die ockergelbliche Farbe der Vorderbrust reicht bis auf den Kropf, welcher ganz ungefleckt erscheint; das auffallendste am griechischen Vogel aber ist die grosse Ausdehnung der schön karmoisinroten Farbe, die sich von dem Unterschwanzdeckgefieder bis auf die Hinterbrust erstreckt und in Form eines überlagerten Anflugs langsam gegen die Vorderbrust hin verklingt. Die Brustseiten sind etwas lebhafter geschaftet wie bei den deutschen Vögeln und diese Schaftflecken konvergieren gegen die Mitte der Brust, die selbst allerdings frei bleibt, wenigstens vorne, denn auf der Hinterbrust zeigen sich wieder lange und schmale Schaftflecke.

Es mag nicht unwillkommen sein, wenn ich hier die Beschreibung des kleinasiatischen Mittelspechts, welcher mir in 2 frisch erlegten Exemplaren aus Konstantinopel vorlag (wegen vorgeschrittener Verwesung liess sich nur das eine konservieren, das Geschlecht war bei beiden nicht mehr zu eruieren), folgen lasse:

Die ganze Unterseite ist auffallend kräftig koloriert und zwar bis gegen den Bauch hin ausgesprochen rostgelblich, die Brust, ausgenommen die mittlere Partie, zeigt breite schwarze Schaftstreifung; der einzelne Schaftstreif nimmt das letzte Drittel der Feder ein und geht bis an deren Ende, das auch zunehmend gelber sich färbt. Etwa auf der Grenze von Brust und Bauch, jedenfalls nicht viel höher, beginnt die blutrote Farbe der Unterleibsmitte; obwohl auch hier nur die Federenden rot sind, so ist doch das Kolorit ein gleichmässiges und ununterbrochenes. Diese Farbe geht mehr in Karmin über auf Steiss und Unterschwanzdecken. Die Kopffedern sind bis über die Hälfte ihrer Länge stark karminrot glänzend; rote Federspitzen finden sich bis auf die übrigens bräunliche Stirn. Der Schnabel erscheint bläulich schwarz, die Füsse hornschwarz.

Von den beiden Vögeln ist das beschriebene Exemplar vom F'ebruar auf dem Vorderkörper etwas kräftiger koloriert, dürfte daher ein Männchen darstellen. Bezüglich der seitlichen Schwanfederzeichnung weicht die kleinasiatische Form sowohl vom mitteleuropäischen, wie von griechischen Mittelspechten ab. Sie ist vielleicht auch etwas stärker, was aus dem kräftigeren Schnabel hervor zu gehen scheint; doch muss ich bemerken, dass das Flügelmass bei dem ersten Vogel im frischem Zustande, nicht am Balg genommen wurde und deshalb wohl etwas reichlich ausfiel. Nach 
Hargitt ${ }^{1}$ ) wäre dieser Specht kleiner als die Stammform, was aber sicherlich nicht richtig ist. Nach allem steht der griechische Mittelspecht dem kleinasiatischen nahe, aber er darf nicht damit vereinigt werden; dass Kollib a y ${ }^{2}$ ) sogar die Süddalmatiner einfach dem $D$. medius sanctijohannis subsummiert, halte ich nach meinen Befunden für etwas voreilig; der die westliche Balkan-Halbinsel bewohnende Mittelspecht bildet, wie so viele andere Formen, nur ein Mittelglied zwischen den Vögeln des Nordens und des Südostens. Soll dieser Specht benannt werden, so schlage ich den Namen $\boldsymbol{D}$. medius splendidior vor. Schon im relativ nahen Ungarn, also in Gebieten mit Kontinentalklima, haust der typische mitteleuropäische Vogel, bei welchem, so prächtig hochkarminrot auch der Kopf manchmal gefärbt sein mag, doch Hinterbrust und Bauchgefieder immer nur licht karminrot überwaschen erscheinen, während die rostgelbliche Farbe meist als verhältnismässig schwacher Anflug auf die Vorderbrust beschränkt bleibt oder nur ausnahmsweise tiefer herabreicht.

Ich gebe nun die Masse aller mir vorliegenden Stücke der Species D. medius:

Coll. P. 1) o ad. Konstantinopel, 18. II. 1903: L. t. 225; a. 134;

[r. 27.

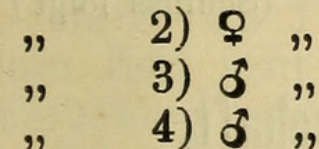
Hag Säranti
15. V. 1904 : a. $126 ;$ r. 26,5 .
$\begin{array}{ll}\text { Hag Saranti } & \text { 31. XI. 03: a. } 125 ; \text { r. } 24 . \\ & \text { 31. XI. 03: a. } 125 ; \text { r. } 27,3 .\end{array}$

Orn."Ges. 5) - ",

Coll. P. 6) - ,

Mus. mon. 7) б"

Gerolfing (Bayern) 20.III. 98: a. 118,5; r. 23,5.

Roggenburg , VIIl. 99: a. 120; r. 25.

Deutschland(H.v.L.) 25.III. 28: a. 123; r. 25,2 .

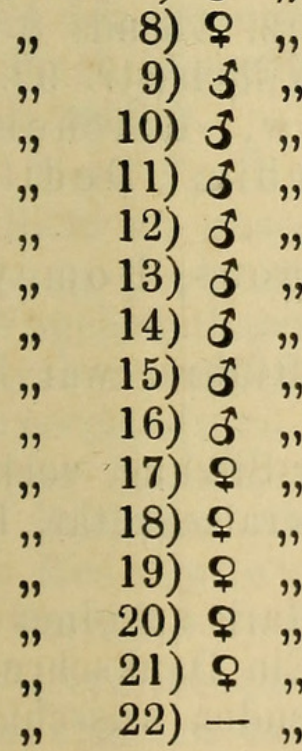

$\begin{array}{llll}" & " & 28 . I I I .28: \text { a. } 124 ; \text { r. } 24,75 . \\ & " & \text { a. } 124 ; \text { r. } 24,75 . \\ & " & \text { a. } 124 ; \text { r. } 24 .\end{array}$

Diös Jenö, 15." I. 95 . a. $122 ;$ r. 25.

$" \quad, \quad 18$. III. 95 a. $125 ;$ r. 25.

",$\quad$ 19. IV. 94 . a $123 ;$ r. 26,5 .

$" \quad$ " 23. I. 95 a. 121 ; r. 25,5 .

$" \quad$ " $\quad$ 22. V. 95 . a. 117 ; r. 24.

$" \quad$ 10.IX. 97 a. $126 ;$ r. 25.

$, \quad, \quad 9$. IX. 97.

a. $125 ;$ r. 26,5 .

23. V. 95 a. $122 ;$ r. 25,5 .

19. IV. 94 a. $126 ;$ r. 25.

8. II. 97 a. $126 ;$ r. 25,5 .

23. V. 95 a. $123 ;$ r. 24,75 .

" $" \quad " \quad-\quad$ a. $123 ;$ r. 25.

1) British Catalogue XVIII, p. 288.

2) Journ. f. Ornith. 1904, p. 497. 
556 Dr. Parrot: Eine Reise nach Griechenland und ihre Ergebnisse.

\section{Dendrocopus minor danfordi (Harg.)}

Ein aus Hag Saranti stammendes altes Männchen vom 17. Dezember 1903 zeichnet sich durch relativ geringe Flügellänge und dadurch aus, dass die Unterseite stark braun überlaufen ist, ferner, dass der Fleck auf der Seite des Hinterhalses eine rahmweisse Farbe trägt. Der schwarze Verbindungsstreif von der Ohrgegend nach dem Hinterkopf ist nur undeutlich sichtbar; hier die Masse: a. 85 ; c. 58 ; r. 15 . Es gehört also dieses Exemplar entschieden zur Form danfordi, welche durchgängig kleinerere Dimensionen zeigt, als mitteleuropäische Stücke. 6 Vögel aus Ungarn, Männchen und Weibchen, messen: a. 87,2 -- $90 ;$ r. 14,5 - 17,3. Interesse bietet ein mir vorliegendes Weibchen aus Mostar, das bei einer Flügellänge von $88 \mathrm{~mm}$ und einer Schnabellänge von nur $14 \mathrm{~mm}$, ausnehmend klein aussieht und dabei einen solchen deutlichen bräunlichen Anflug auf der ganzen Unterseite erkennen lässt, dass man geneigt sein möchte, den Vogel viel eher zu danfordi als zu minor zu nehmen. Haben wir hier auch ein nur intermediäres Stück vor uns, so dürfte es sich doch ergeben, dass die Form danfordi in den litoralen Gebieten weiter nach Norden hinaufgeht, als man bisher annahm. Sharpe ${ }^{1}$ ) gibt als Verbreitung für diese Unterart Kleinasien, Türkei und Griechenland an.

(Schluss folgt.)

\section{Deutsche Ornithologische Gesellschaft.}

\section{Bericht über die März-Sitzung 1905.}

Verhandelt Berlin, am Montag, den 6. März, Abends 8 Uhr, im Sitzungszimmer, Architekten-Vereinshaus, Wilhelmstr. 92.

Anwesend waren die Herren: Schalow, Reichenow, Grunack, von Treskow, Haase, Matschie, Deditius, Heinroth und von Lucanus.

Als Gäste beteiligten sich die Herren Selmons, Domeyer, Staudinger und Borchmann.

Den Vorsitz hatte Herr Schalow, Schriftführer war Herr Matschie.

Nachdem der Bericht über die Februar-Sitzung verlesen und angenommen worden war, machte der Generalsekretär, Herr Reichenow, einige geschäftliche Mitteilungen.

Der Vorstand hat einen Beitrag von 40 Mark zu einer Gedenktafel für Temminck in Leiden bewilligt. Ein Dankschreiben des für diese Angelegenheit in Holland bestehenden Ausschusses ist eingelaufen.

Ferner wurde das Programm für den Internationalen Ornithologen-Kongress in London verlesen und die vorläufige Tagesordnung

1) Handlist of the genera and species of birds, p. 215. 


\section{$2 \mathrm{BHL}$ Biodiversity Heritage Library}

1905. "Eine Reise nach Griechenland und ihre ornithologischen Ergebnisse." Journal $f u$

r Ornithologie 53, 515-556. https://doi.org/10.1007/bf02094927.

View This Item Online: https://www.biodiversitylibrary.org/item/107488

DOI: https://doi.org/10.1007/bf02094927

Permalink: https://www.biodiversitylibrary.org/partpdf/142376

\section{Holding Institution}

Smithsonian Libraries

\section{Sponsored by}

Biodiversity Heritage Library

\section{Copyright \& Reuse}

Copyright Status: Public domain. The BHL considers that this work is no longer under copyright protection.

This document was created from content at the Biodiversity Heritage Library, the world's largest open access digital library for biodiversity literature and archives. Visit BHL at https://www.biodiversitylibrary.org. 